\title{
An assessment on the unsteady flow distortion generated by an S-duct intake
}

\author{
Matteo Migliorini*, Pavlos K. Zachos ${ }^{\dagger}$ and David G. MacManus \\ Propulsion Engineering Centre, School of Aerospace Transport and Manufacturing, \\ Cranfield University, MK43 OAL, Cranfield, UK
}

\begin{abstract}
Closer integration between the fuselage and the propulsion system is expected for future aircraft to reduce fuel consumption, emissions, weight and drag. The use of embedded or partially embedded propulsion systems may require the use of complex intakes. However, this can result in unsteady flow distortion which can adversely affect the propulsion system efficiency and stability. This works assesses the characteristics of the unsteady flow with a view to the potential flow distortion presented to the compression system. Particle image velocimetry is used to measure the flow distortion generated by an S-shaped intake. The timeresolved tracking of the idealized relative incidence angle revealed that most frequent distortion events exhibited $90^{\circ}$ exposure sector and up to $\pm 5^{\circ}$ mean relative incidence. The imposition of a thicker boundary at the $S$-duct inlet increased the probability of distortion events that are characterized by a longer exposure sector and higher relative incidence angles. Because of these characteristics, the distortion caused by the S-duct intake could induce instabilities that are detrimental for the propulsion system performances and stability. Overall, this work proposes a new method to assess the possible relative incidence angle on the compressor rotor taking into account the intake flow unsteadiness.
\end{abstract}

$$
\begin{aligned}
& \text { AIP }=\text { aerodynamic interface plane } \\
& D_{\text {in }}=\text { S-duct inlet plane diameter, } \mathrm{mm} \\
& D_{\text {out }}=\text { S-duct outlet plane diameter, } \mathrm{mm} \\
& \mathrm{EO}=\text { engine order } \\
& f_{s}=\text { TR-PIV acquisition frequency, } \mathrm{Hz} \\
& \mathrm{H} \quad=\text { S-duct vertical offset } \\
& \mathrm{L} \quad=\text { S-duct length } \\
& \mathrm{M}=\text { Mach number } \\
& r=\text { radial coordinate, } \mathrm{m} \\
& \operatorname{Re} \quad=\text { Reynolds number } \\
& \text { St }=\text { Strouhal number, } \\
& t=\text { time step, ms } \\
& u=\text { rotational speed of the rotor, } \mathrm{m} / \mathrm{s} \\
& v \quad=\text { absolute velocity component, } \mathrm{m} / \mathrm{s} \\
& w=\text { relative velocity component, } \mathrm{m} / \mathrm{s} \\
& \alpha=\text { absolute swirl angle, }{ }^{\circ}, \tan ^{-1}\left(v_{\theta} / v_{z}\right) \\
& \beta_{\text {flow }}=\text { relative flow angle, }{ }^{\circ} \\
& \beta_{\text {metal }}=\text { rotor inlet metal angle, }{ }^{\circ} \\
& \delta=\text { boundary layer thickness, } \mathrm{mm} \\
& \theta_{b}=\text { angular position of the blade, }{ }^{\circ} \\
& \iota \quad=\text { relative incidence angle, }{ }^{\circ}
\end{aligned}
$$

\section{Nomenclature}

\footnotetext{
* PhD Student, Propulsion Engineering Centre, Member AIAA.

${ }^{\dagger}$ Lecturer, Propulsion Engineering Centre, Member AIAA.

* Professor, Propulsion Engineering Centre, Member AIAA.
} 


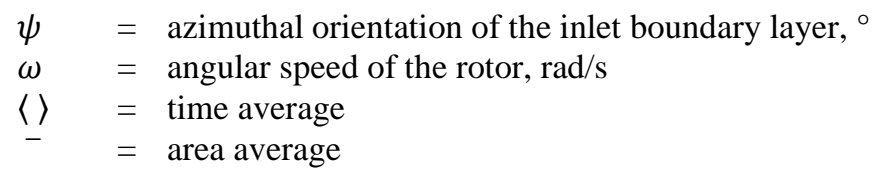

\section{Introduction}

Understanding the engine response to the inlet flow distortion is a crucial requirement for the integration between intake and propulsion system. Since the 1960s, many researchers have simulated the inlet distortion numerically and experimentally and evaluated the effect on the engine performance [1]. First experiments on engine stability monitored the compressor pressure ratio when the inlet was exposed to different sectors of pressure distortion [2] and it was found that sectors of circumferential total pressure loss $60^{\circ}$ to $90^{\circ}$ can reduce the engine surge margin. In addition, and within this context, some industry guidelines [3] suggest that $25^{\circ}$ is a critical angle for spoiled sectors. Further research has been undertaken to establish the critical disturbances for the engine stability and to identify the key frequency and extent signatures [4]. Rather than a single critical frequency, researchers identified a range of disturbances frequencies to which the engine responds. Many of these studies showed that disturbances with a signature frequency of about 1 Engine Order (EO) could reduce the compressor surge margin [5,6]. On the other hand, it is considered that for unsteady disturbances with a frequency substantially lower than 1EO the engine responds in a quasi-steady manner. More recently, the response time has been evaluated considering the time for a disturbance to travel from the blade leading edge to the throat of the blade passage [7]. For axial compressors, 4 to 5 blades have to be affected by the disturbance in order to observe a change in the stability limit of the compression system map [7,4]. Frequencies of the order of 1EO also interest they could also excite the first resonant frequency of the compressor rotor blades, which is typically $\mathrm{St}=0.7$ for model scale compressor [8]. These long-length-scale disturbances are typical of just one of the stall inception mechanisms, known as modal stall inception [9]. On the other hand, also shortlength-scale disturbances can be a source of instability, since they could trigger the spike-type inception [9]. Silkowski's experiment [10] showed that the velocity disturbance of a length scale of 3 blade pitches and an amplitude defect of $30 \%$ of the rotor tip speed triggered the stall inception. However, there is not a general rule to predict the engine response for different inlet distortion. Published research indicates a typical range between 1-per-rev and blade passing frequency for disturbances that could contribute to the instability of a compression system [11].

Recently, there has been an increasing interest in engine stability assessments for closely-coupled propulsion systems of the new generation of aircraft. The flow interaction with the fuselage and the implementation of curved intakes causes total pressure and swirl distortion, which can be critical for the engine operation and can cause stall inception and uneven blade loading. Stereo Particle Image Velocimetry (SPIV) has been used to characterize the flow distortion of convoluted intakes in the work of Zachos et al. [12]. SPIV provided synchronous, non-intrusive measurements to characterize the swirl distortion and the flow unsteadiness with a spatial resolution which is 2 orders of magnitude greater compared with conventional pressure transducers arrangements [13]. The dynamic and steady swirl distortion was found to be more pronounced in ducts with an high centerline offset [14]. The most energetic coherent structures found with proper orthogonal decomposition [15] show that the flow is governed by a lateral swirl switching mode and a vertical mode. These flow modes promote the bulk swirl events and the twin swirl events at the aerodynamic interface plane [14]. Investigations on how to reduce the peak swirl unsteadiness with vortex generators are reported by Tanguy et al. [16]. These devices suppressed the primary unsteady flow switching mechanism and therefore the extreme events that lead to high swirl intensity. More recently, time-resolved particle image velocimetry (TR-PIV) was used to assess the frequencies associated with the flow distortion modes [17]. The frequencies of the coherent structures are contained within St $<1.2$ and therefore they are within the range of the critical frequencies for the propulsion system. Within this context, the current work aims to assess the extent, the magnitude and the probability characteristics of the flow distortion generated with S-duct intakes. The scope is to determine if the characteristic frequencies of the flow distortion of these intakes fall within the critical frequency ranges. The flow field data captured with time-resolved particle image velocimetry is analyzed considering the distortion in an envisaged relative frame of reference for a sample compressor geometry [18]. The relative incidence angle on the rotor will be tracked by evaluating a notational rotation of the rotor in the flow field through the time coupling between the acquisition data and the rotational speed of the rotor. A frequency-based filter is applied to the measured velocities to discriminate which disturbances, among all the spectrum of frequencies, could cause the instability of the compressor. 


\section{A. Experimental facility TR-PIV specifications}

\section{Methods}

The experiments were conducted in a complex intakes experimental facility [12]. It is designed to accommodate different $\mathrm{S}$-shaped geometries. The flow is sucked from the chamber upstream of the bell-mouth intake and it is driven into a flow conditioning section where a flow straightener is placed to reduce the turbulence of the inlet flow (Fig. 1). At station 3 (Fig. 1), 2.55D in upstream the S-duct entry plane, pressure distortion gauzes can be optionally placed to synthetically generate total pressure profiles. In this work, an honeycomb screen has been used to produce a boundary layer-type velocity profiles, with a thickness of $\delta / \mathrm{D}_{\text {in }}=0.332$ (Profile A) [19], which is thicker than the nominal boundary layer of the rig $\left(\delta / \mathrm{D}_{\text {in }}=0.04\right)$. The S-duct geometry features a relative high offset $S$-duct $\left(H / \mathrm{D}_{\text {in }}=2.44\right)$ and it is similar to the S-duct intake investigated by Garnier et al.[20]. The intake features an inlet section of $D_{\text {in }}=121.6$ $\mathrm{mm}$ and it diffuses to an outlet section of $\mathrm{D}_{\text {out }}=150 \mathrm{~mm}$ (Fig. 1). A cylindrical glass section is placed downstream the S-duct to enable optical access for the flow measurements. Downstream of the transparent section, a diffuser duct drives the flow to the suction fan (Fig. 1). The operating point of the rig is set by the velocity of the flow measured in the section upstream the $\mathrm{S}$-duct, at $1.45 \mathrm{D}_{\text {in }}$ upstream the $\mathrm{S}$-duct entry plane. This is set at $\mathrm{M}_{\mathrm{ref}}=0.27$ and the reference Reynolds number is $\operatorname{Re}_{\mathrm{D}}=7.38 \times 10^{5}$.

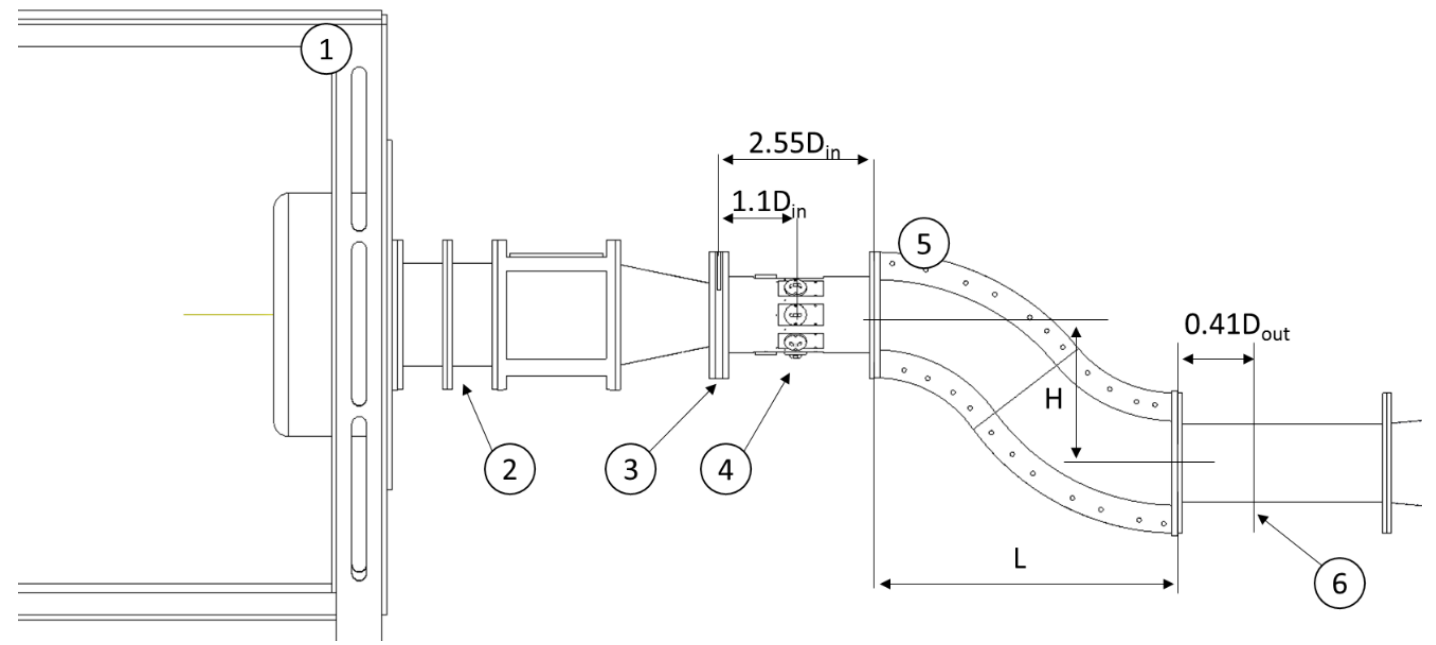

Fig. 1: Cranfield test facility schematic: 1- seeding chamber, 2- flow conditioning section, 3- honeycomb screen section, 4- pressure measurements ports, 5- S-duct, and 6- PIV measurement plane.

\section{B. TR-PIV specifications}

In the seeding chamber (Fig. 1), the flow was seeded with Di-Ethyl-Hexyl Sebacate particles with an average diameter of approximately $1 \mu \mathrm{m}$, generated with a Laskin nozzle. The measurement plane is placed $0.41 \mathrm{D}_{\text {out }}$ downstream of the S-duct exit plane $(61 \mathrm{~mm})$, where a dual cavity pulsed Nd:YAG laser illuminates the particles on a cross section. The images are taken by a pair of CMOS cameras placed in a stereo arrangement. The cameras featured a frame resolution of $1280 \times 800 \mathrm{px}(1 \mathrm{MP})$ and a maximum straddle frame rate of 16,600 fps. The acquisition frequency is set at $4 \mathrm{kHz}$, which is 10 times greater than dominant flow frequency that is around $S t=1.0$ as predicted by the DDES simulations conducted by Gil-Prieto et al. [21]. Each TR-PIV dataset consists of 20,000 instantaneous velocity snapshots, which are sufficient for the convergence of the out-of-plane velocity component and its standard deviation to within $0.2 \%$ and $0.4 \%$ respectively [17]. The cameras have a pair of AF 1.8/D Nikkor lenses with a focal length of $60 \mathrm{~mm}$. A single plane calibration target was traversed axially to correlate the pixel shift into a physical displacement. The velocity fields are obtained with a direct correlation method and a recursive multi-pass window approach. The initial window size was set at $128 \times 128 \mathrm{px}$ and the final pass was set at $32 \times 32 \mathrm{px}$, with a window overlap of $50 \%$. The cameras captured the flow with a vector resolution of $0.0153 \mathrm{D}_{\text {out }}(2.3 \mathrm{~mm})$ in both directions across the AIP. Only the data within $r<0.95 R_{A I P}$ is considered in this analysis, in order to remove the influence of spurious vectors near the domain boundaries caused by laser light reflections. This results in a total of approximately 2900 vectors across the AIP. The disparity correction reduced the bias errors due to misalignment between the laser light and the calibration plate. The estimated uncertainty with the method described by Raffel et al. [22] is $2.6 \%$ of the area-averaged, time-averaged out-of-plane velocity at the AIP. 


\section{Notional assessment of relative frame of reference distortion}

Much of the previous computational and experimental work focused on the assessment of intake flow distortion for a range of geometries $[23,24,17]$ as well as for the effect of various flow control methods $[25,26,20,16]$. Although some experimental studies have included a rotating compression system in conjunction with either prescribed distortion or a complex intake [19], the measurements of the unsteady distorted flow fields for these cases are very limited. The body of work on canonical test cases such as S-ducts with circular cross sections has typically evaluated the steady and unsteady distortion in an absolute frame of reference. This has been within the context of the related industry standard metrics which are also based on an absolute frame of reference. It is acknowledged that there is an interaction between the compression system and the distortion which arises from the complex intakes [16]. In particular for a typical transonic fan and spinner the local acceleration and massflow redistributions will tend to reduce the swirl angle unsteady distortion. However, the previous studies using TR-PIV provided rich measurement data sets which quantified the detailed unsteady characteristics of the absolute velocity distortion [17] for intakes in the absence of the compression system. Consequently, it is of interest to evaluate the distortion from the potential perspective of the rotating machinery and in the relative frame of reference. This is possible with the TR-PIV data which provides synchronous 3 components of velocity across the AIP with sufficient temporal resolution. Within this context, one of the aims of the current work is to make an evaluation of the complex unsteady velocity distortion in a hypothesized relative frame of reference. For the example here, the analysis is based on the established Rotor 67 configuration [18].

The velocity data captured with TR-PIV is converted in the relative frame of reference of the compressor rotor to investigate the characteristics of the relative incidence angle. The compressor geometry is downscaled to the rig configuration $\left(D_{\text {out }}=150 \mathrm{~mm}\right)$ and the rotational speed has been modified to conserve the same ratio between the axial and tangential velocity of the original rotor design for a mid-span position. This preserves the ideal relative flow angle at the nominal rotor inlet, and yields an axial velocity to rotor speed ratio of $v_{z} / u=0.798$ and an axial Mach number of $\mathrm{M}=0.18$.

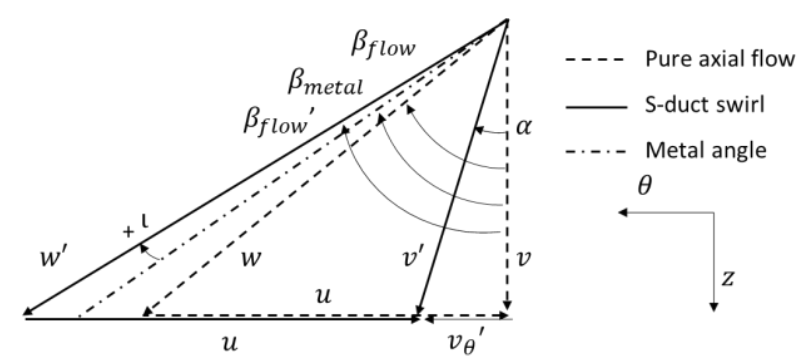

Fig. 2: Triangles of velocities at the rotor leading edge in case of pure axial inlet flow (dashed line) and in case of swirl distortion (continuous line).

Fig. 2 shows a sketch of the nominal velocity triangles for the hypothesized rotor inlet condition. The dashed lines represent the velocities for ideal axial flow at the inlet, where $v$ is the absolute velocity, $u$ is the rotational velocity, $w$ is the relative velocity and $\beta_{\text {flow }}$ is the relative flow angle. The continuous lines represent the velocity triangle in the case of a local swirl distortion arising from just a change in the tangential velocity $v_{\theta}{ }^{\prime}$. In Fig. 2, $\alpha$ is the absolute swirl angle, $v^{\prime}$ is the absolute velocity, $u$ is the rotational velocity, $w^{\prime}$ is the relative velocity and $v_{\theta}{ }^{\prime}$ is the tangential component of the absolute velocity $v^{\prime}$.

The relative velocity is:

$$
\begin{gathered}
\overrightarrow{w^{\prime}}=\overrightarrow{v^{\prime}}+\vec{u} \\
|u|=\omega r
\end{gathered}
$$

where $\omega$ is the rotational speed of the rotor and $r$ the radius. The relative flow angle in case of swirl distortion is:

$$
\beta_{\text {flow }}{ }^{\prime}=\tan ^{-1}\left(w_{\theta}{ }^{\prime} / v_{z}{ }^{\prime}\right)
$$

where $w_{\theta}{ }^{\prime}$ is the tangential component of the velocity vector $w$ and $v_{z}$ ' is the axial component of the absolute velocity $v^{\prime}$. The relative incidence angle on the rotor blades is the difference between the relative flow angle and the inlet metal angle of the rotor (dash-dot line in Fig. 2):

$$
\mathrm{\iota}=\beta_{\text {flow }}{ }^{\prime}-\beta_{\text {metal }}
$$




\section{Exposure time, intensity and probability of distortion events}

The TR-PIV dataset consist in 20,000 instantaneous velocities fields taken with an acquisition rate of $4 \mathrm{kHz}$. The aim of this work is to assess the flow distortion from these datasets for the hypothesized evaluation in terms of the relative incidence for R67. The flow distortion is measured in a relative frame of reference and is characterized by temporal variations across a range of frequencies and spatial variations across a first order range of length scales. From the perspective of the rotating compressor blades it is necessary to also consider a variety of time-scale and space locations relative to the unsteady S-duct flow distortion. For example, for a nominal rotor rotating around the annulus it will experience different levels of flow distortion at different azimuthal positions all of which are also changing in time. Therefore the level of unsteadiness onto the nominal rotor leading edge will depend on both the rotation speed of the rotor, the unsteady variations in the flow distortion and the spatial extent and severity of the distortion. The distortion for a nominal rotor as it rotates around the annulus will depend on the nominal starting position within the duct as well as the nominal starting time relative to the unsteady distortions. Therefore, it is necessary to evaluate the distortion for each potential azimuthal position of each rotor within the blade row relative to the full unsteady flow measurements which encompass the equivalent of several hundred rotations of the rotor. Clearly, for each rotor, the unsteady distortion will also be different across the rotor from the hub to tip positions. The nature of the TR-PIV data which provides synchronous three component velocity fields across the AIP at a sufficient temporal resolution enables all of these factors to be assessed for the first time. Conventional unsteady total pressure measurements on fixed rakes cannot provide this information. Similarly, unsteady data from typical five-hole probe devices do not provide the required synchronous spatial resolution to enable such an evaluation. Within this context, the R67 has a set of 22 blades and for the equivalent condition scaled to the current rig flow coefficient $\left(v_{z} / u\right)$, the idealized rotation speed is $14754 \mathrm{rpm}$, with a $1 \mathrm{EO}$ frequency of about $245 \mathrm{~Hz}$. This means that the compressor rotor virtually performs more than 1200 revolutions within the total acquisition time of the TR-PIV dataset. The acquisition frequency of the TRPIV is at $f_{s}=4 \mathrm{kHz}$, therefore the time step between two successive snapshots is $\Delta t_{P I V}=1 / f_{s}=0.25 \mathrm{~ms}$. Therefore, for a rotor blade 0 positioned at the reference angle $\theta_{b 0}=0^{\circ}$ at the time $t_{0}$, at the time $t_{1}=t_{0}+\Delta t_{P I V}=0.25 \mathrm{~ms}$, the blade will be at:

$$
\theta_{b 0}\left(t_{1}\right)=\theta_{b 0}\left(t_{1}\right)+\omega\left(t_{1}-t_{0}\right)=22.1 \mathrm{deg}
$$

where $\omega$ is the rotor speed in rad/s. The rotor speed is kept constant, therefore at snapshot $t_{2}=2 \Delta t_{P I V}=0.50 \mathrm{~ms}$, blade 0 will be at $\theta_{b 0}\left(t_{2}\right)=44.2 \mathrm{deg}$. This is illustrated in Fig. 3 which shows the blade rotation for 3 PIV snapshots where the flow distortion in terms of relative incidence is also changing in time and spatial distribution. The distribution of the relative incidence angle across the rotor inlet highlights the unsteadiness of the incidence angle between different moments in time (Fig. 3). The variability of the incidence angle on the rotor blades depends on the time at which the relative incidence is measured and the circumferential position of the blade in the time instant. This time-coupling between the virtual rotor rotation and the TR-PIV dataset considers both the sources of variability. 

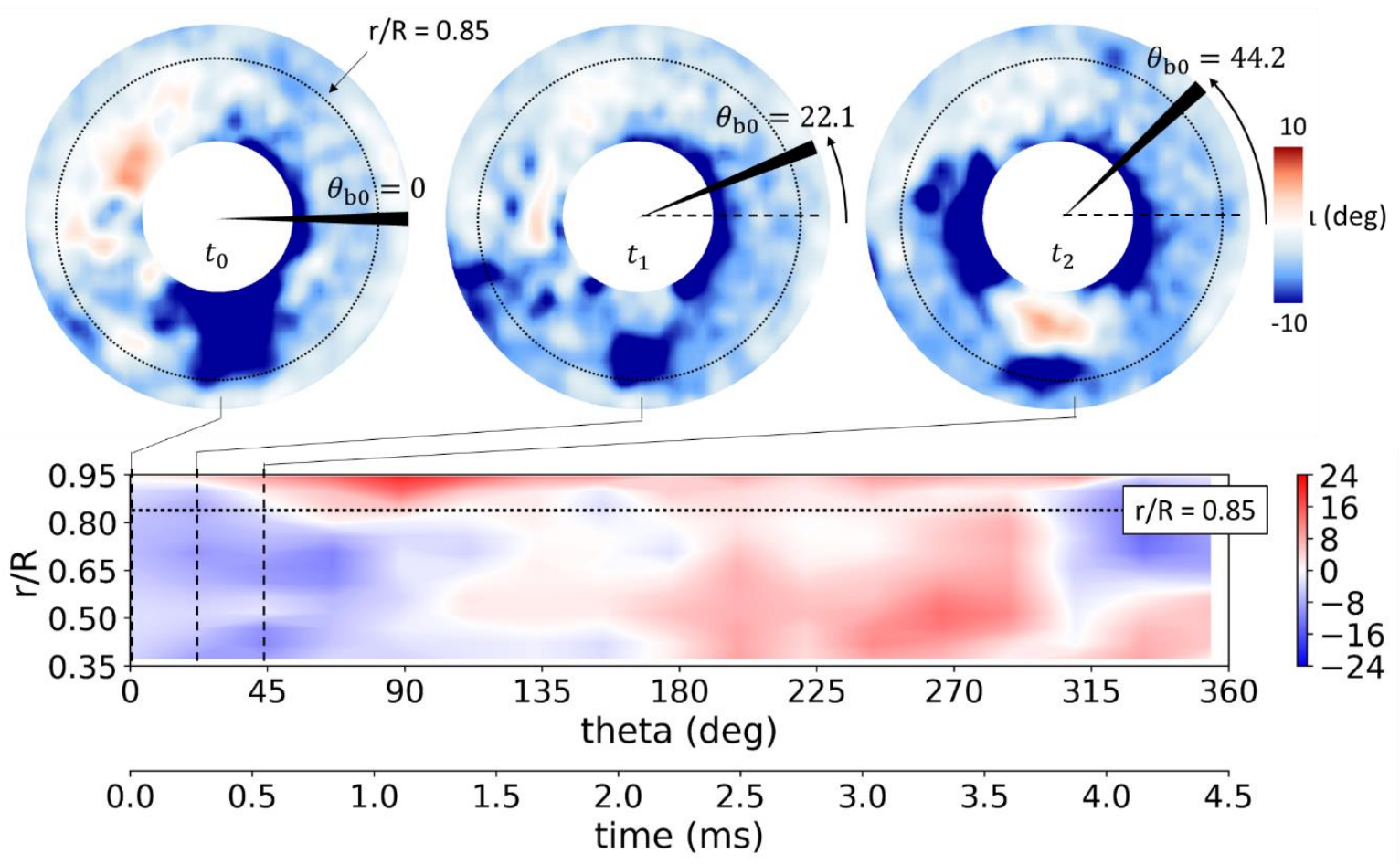

\section{$\begin{array}{lllllllllllllllll}0 & 1 & 2 & 3 & 4 & 5 & 6 & 7 & 8 & 9 & 10 & 11 & 12 & 13 & 14 & 15 & 16\end{array}$ \\ PIV time step $t_{i}$}

Fig. 3: Time coupling between the TR-PIV dataset snapshots and the virtual rotation of the compressor rotor.

The tracking of the relative incidence angle has been performed separately for different radial positions. Analogous with the swirl distortion descriptor definitions [3], the fluctuations of the incidence angle are classified as distortion events. Each distortion event is described by two quantities: the exposure time and the magnitude (Fig. 4). The exposure time $\left(t_{e}\right)$ is defined as the period of time between two changes of sign of the incidence angle. Thus, it represents the effective duration of the distortion event in the relative frame of reference for the particular tracked rotor. In other words, it represents what the individual rotor blade experiences during the particular rotation relative to the start of the unsteady data. On the other hand, the magnitude can be quantified either with the mean $\left(\langle\iota\rangle_{e}\right)$ or with the peak value $\left(l_{\text {peak }, e}\right)$ of relative incidence angle within each distortion event. Thus, it quantifies the intensity of the distortion event and, from a mechanical stress perspective, an aspect which affects the potential changes in blade loading. 

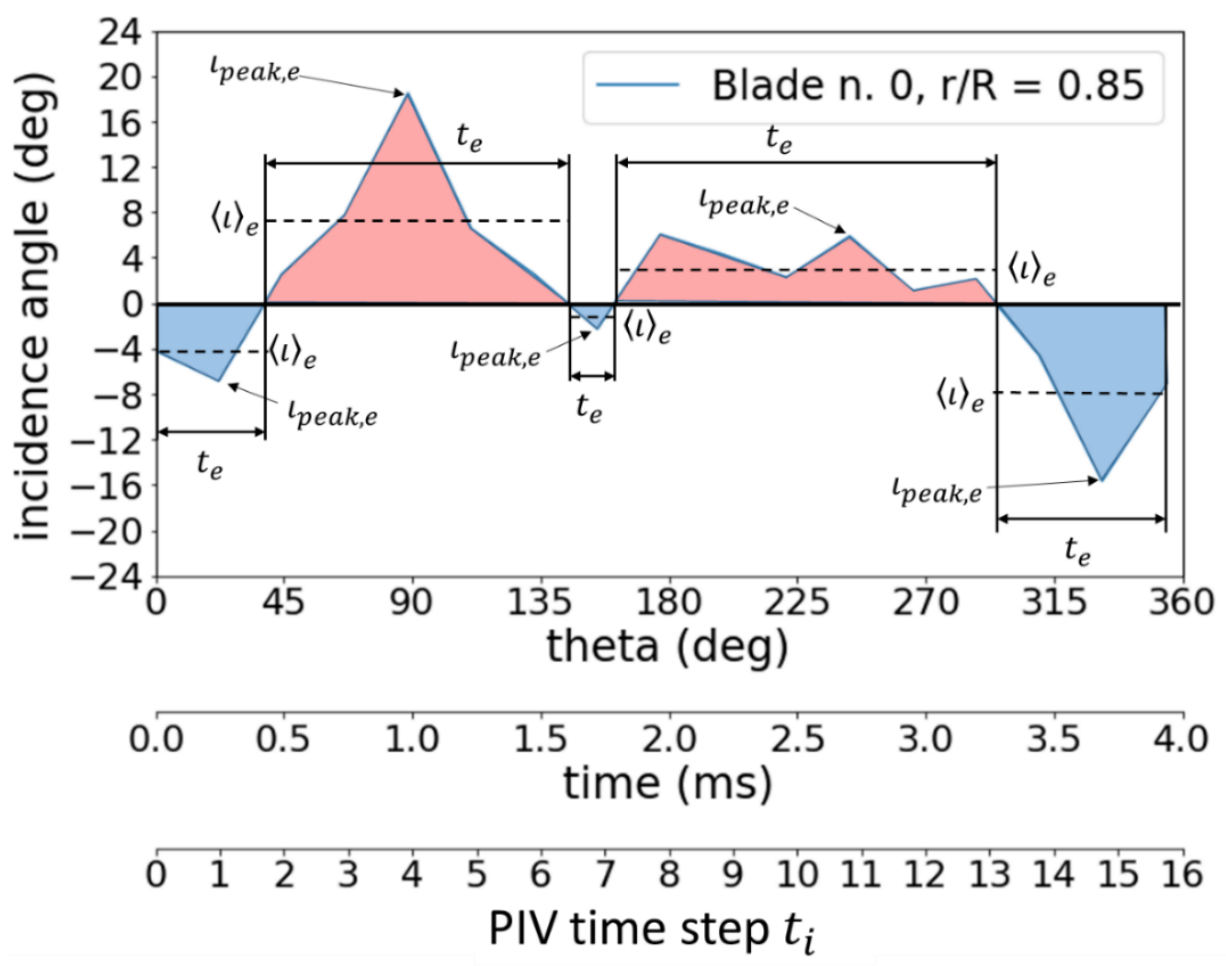

Fig. 4: Classification of the distortion events by the change in sign of the incidence angle.

Some steps were taken to maximize the spatial and temporal resolution of the time coupling scheme between the rotor and the TR-PIV dataset. Although the relative incidence tracking has been highlighted for just one blade (Fig. 3 ), it applies for all the blades of the rotor. The position of each blade is defined at any instant in time as $\theta_{b n}\left(t_{i}\right)$, where $t_{i}$ is a generic time step of the TR-PIV dataset and $n$ identifies a generic blade. Thus, the relative incidence can be evaluated for each blade as a function of:

$$
\iota_{b n, r}=\iota\left(\theta_{b n}, r\right)
$$

Where $\theta_{b n}\left(t_{i}\right)$ is the circumferential position of the $n$-th blade in the velocity field, $r$ is the radial coordinate and $n=$ $\left[0, N_{\text {blades }}\right]$ with $N_{\text {blades }}$ the total number of blades.

This increases the number of samples by a factor equal to the number of blades. For example, in this work, the number of samples of relative incidence considering only one blade and one radial position $\theta_{b 0}\left(t_{i}, r / R=0.85\right)$, is 20,000 , which is the number of instantaneous velocity snapshots in the TR-PIV dataset. Instead, considering all the 22 rotor blades [18] at one radial position $\theta_{b n}\left(t_{i}, r / R=0.85\right)$, the number of total samples increases to 440,000 .

However, some distorted regions which are measured with the TR-PIV could still be omitted in this analysis. For example, if a distorted region is located within the blade pitch $\left(\Delta \theta_{b}=16.3^{\circ}\right)$ in snapshot 1 (Fig. 5a), it would not be captured by measuring the relative incidence angle on adjacent blades at that moment in time. More importantly, it could happen that this event would not be captured in the successive snapshot neither. This could happen if the distortion region persists in the same location in the next time step (Fig. 5b) and it does not coincide with any of the angular position of the blades. Alternatively, it could happen that the distortion region moves circumferentially with a speed very close to the rotor and therefore it will be located always in the non-evaluated part of the blade pitch region (Fig. 5c). Or, finally, it could happen that the distorted region that is in-between the blade pitch at snapshot 1 fades out in snapshot 2 (Fig. 5d). In all these cases, the distorted region is not captured by the time coupling scheme. 


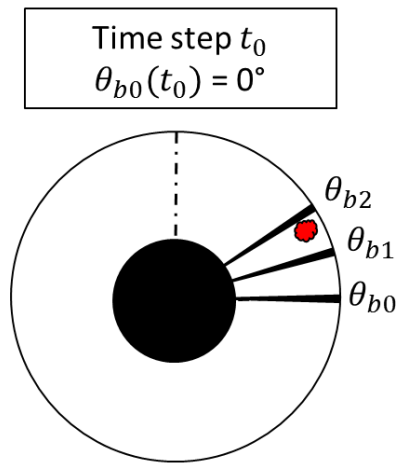

a)

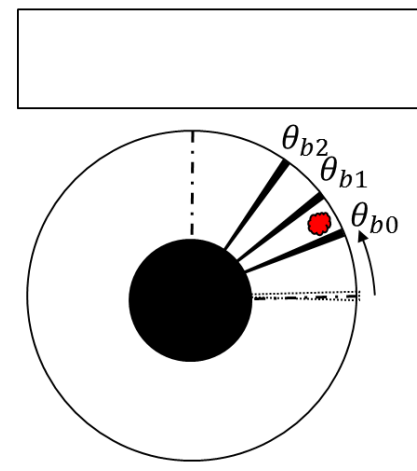

b)

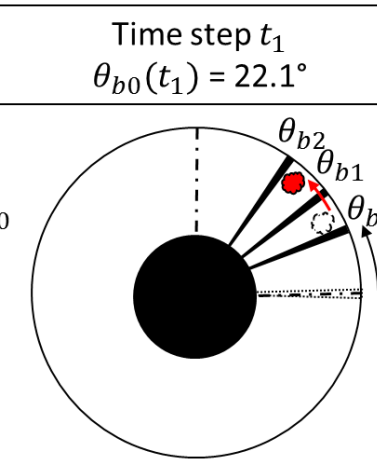

c)

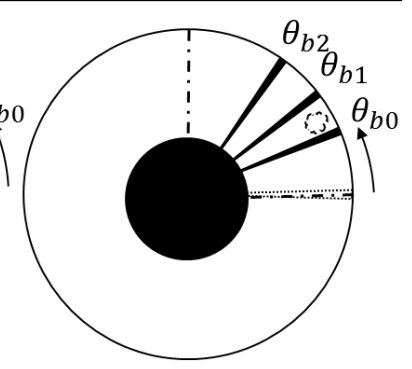

d)

Fig. 5: Distortion events within the blade pitch and between successive time steps.

However, the distorted region of Fig. 5a is captured by the TR-PIV dataset. It is possible to determine that a different azimuthal position of the rotor at snapshot 1 will make at least one of the blades to coincide with the distortion region (Fig. 6). This can happen with a different starting position of the rotor at the beginning of the TR-PIV acquisition, bearing in mind that the alignment of the rotor initial position is arbitrarily set relative to the temporal start of the TR-PIV acquisition. Therefore, to get a more statistically representative dataset of the potential flow distortion from the perspective of a full rotor set, the rotor has been clocked within a range of angular offset angles within $\Delta \theta_{\text {pitch }}=16.3^{\circ}$. The number of the clocked positions has been defined by the coarsest angular grid resolution of the TR-PIV acquisition at the blades tip $(2.3 \times 2.3 \mathrm{~mm})$, which corresponds to an angle of $\Delta \theta_{\text {clocking }}=1.75^{\circ}$. This equates to $\Delta \theta_{\text {pitch }} / \Delta \theta_{\text {clocking }} \approx 9$ clocking positions. With this construction, the set of clocked Rotor 67 (22 blades) is equivalent to a 206 blade instances and the total number of samples of incidence angle at one radial position $\theta_{b n}\left(t_{i}, r / R=0.85\right)$ is increased from 440,000 to about 4.1 million.

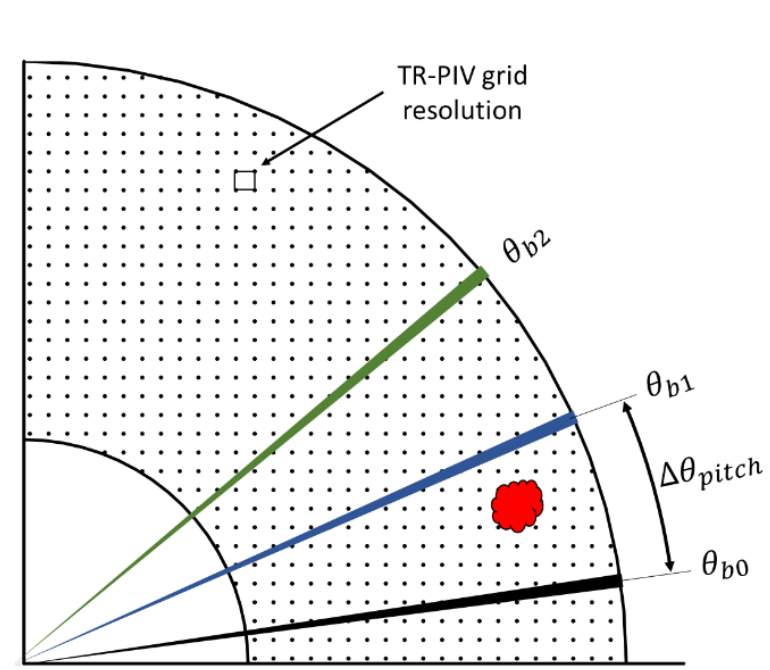

Time step $t_{0}$

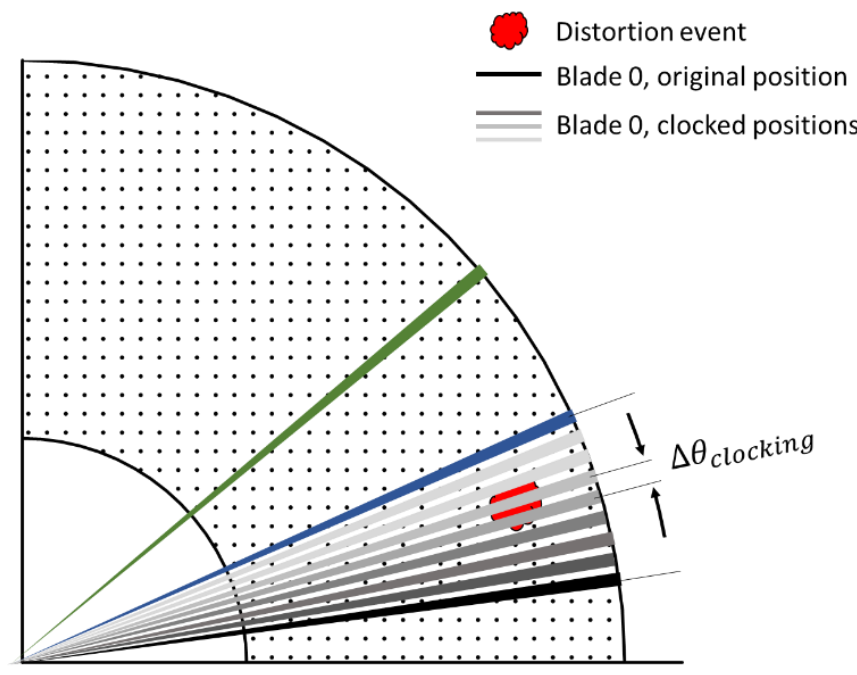

Time step $t_{0}$

Fig. 6: Clocking positions of the rotor to increase the spatial resolution and improve the distortion events detection.

This benefits both the temporal and the spatial resolution, firstly because of the different starting position of the rotor at the beginning of the TR-PIV acquisition, and secondly because of the increase resolution within the blade pitch. Nevertheless, this work presents some limitations. Firstly, this work considers an envisaged relative frame of reference for Rotor 67 . The data is captured at the outlet of the S-duct intake with clean flow without the rotor geometry 
placed in the section. Thus, there is no flow interaction between the rotor blades and the S-duct outlet flow. In addition, only the data in the hub-to-tip annular sector $\left(r>R_{\text {spinner }}\right.$ with $\left.R_{\text {spinner }}=0.372\right)$ is considered to compute the incidence angles. Secondly, the detection of the distortion events is limited by the sampling frequency of the TR-PIV $\left(f_{s}=4 \mathrm{kHz}\right)$. All the distortion events that happen in between the TR-PIV time steps $t_{0}$ and $t_{1}$ (Fig. 5) are not captured. The minimum exposure time for distortion events is defined by the $\Delta t_{P I V}=1 / f_{s}=0.25 \mathrm{~ms}$. For distortion events that are captured at time $t_{0}$ and that disappear in $t_{1}$ (Fig. 5a-d), this study is not able to determine the real physical time of the event, which could be any time interval between 0 and $\Delta t_{P I V}=0.25 \mathrm{~ms}$. In these cases, the exposure time associated with these distortions is set at $\Delta t_{P I V}=0.25 \mathrm{~ms}$.

Finally, only the events with an associated frequency between 0.18 and 2.6 Strouhal number have been included in the analysis, based on the reviewed work on the engine stability assessment presented in the introduction chapter. The outcomes of the studies showed that the instabilities are caused by disturbances that have an associated frequency between $0.3 \mathrm{EO}(S t=0.18)$ and the passing frequency of a 5-blade-sector $(S t=2.6)$. Therefore, prior to the analysis on relative incidence angle, the velocity data has been processed with a bandpass digital filter that has been designed with a $12^{\text {th }}$ order Butterworth function. This ensures that only the frequencies of interest for the engine stability assessment are taken into account in this analysis.

\section{Results}

\section{A. Flow field in the relative frame of reference}

In this section the time-averaged, area averaged velocities at the AIP and incidence angle on R67 are presented (Fig. 7). The velocities are normalized by $\overline{\left\langle v_{z}^{\prime}\right\rangle}$, which is the time-averaged area-averaged out-of-plane velocity at the AIP. The core of the domain has been cropped for $r<R_{\text {spinner }}$ to focus on the nominal blade span of R67 only [18]. The out-of-plane velocity component $\left(v_{z}^{\prime}\right.$, Fig. 7a) shows the typical loss region at the bottom of the section identified in the work of Zachos et al. [12] with a low-bandwidth PIV data on the same high-offset S-duct. The maximum values of the time-averaged out-of-plane velocity component $\left(v_{z}^{\prime}\right.$, Fig. 7a) are in good agreement with the range of velocities previously identified in Gil-Prieto et al. [14] for an inlet Mach number of 0.27. The tangential velocity ( $v_{\theta}^{\prime}$, Fig. 7b) primarily highlights the vertical movement of the secondary flows that are generated within the S-duct. The streamlines highlight the pair of contra-rotating Dean vortices [27] typical of curved ducts. The tangential velocity is one order of magnitude smaller than the out-of-plane component. Thus, the associated time-averaged swirl angle $\alpha$ (Fig. $7 \mathrm{~b}$ ) ranges between $\pm 8^{\circ}$.

In the relative frame of reference of the modified R67 configuration, the relative tangential velocity $\left(w_{\theta}^{\prime}\right.$, Fig. $\left.7 \mathrm{c}\right)$ has a positive bias in the relative time-averaged tangential velocity, since the rotational speed of the rotor $u$ is one order of magnitude greater than the tangential velocity $v_{\theta}^{\prime}$. The gradient of the relative tangential velocity $\left(w_{\theta}^{\prime}\right.$, Fig. 7c) reflects the natural radial gradient of the rotational speed of the rotor. The contra-rotating pattern of the tangential velocity $v_{\theta}^{\prime}$ influences just marginally the time averaged relative tangential velocity. The incidence angle $(\iota$, Fig. $7 \mathrm{~d})$ has been computed between the relative flow angle $\beta_{\text {flow }}^{\prime}$ and the nominal metal angle of R67 ( $\beta_{\text {metal }}$, Fig. 2$)$. The time-averaged contour shows a zone of negative relative incidence in the right part of the domain and a peak of positive relative incidence in the close-to-hub lower half of the domain. The first corresponds to an area with a relatively high axial component $\left(v_{z}^{\prime}\right.$, Fig. $\left.7 \mathrm{a}\right)$ and a modest relative tangential velocity $\left(w_{\theta}^{\prime}\right.$, Fig. $\left.7 \mathrm{c}\right)$, which produce a reduction in the relative flow angle ( $\beta_{\text {flow }}^{\prime}$, Fig. 1$)$ and a consequent negative incidence tendency. The second, instead, corresponds to an area with an axial component $\left(v_{z}^{\prime}\right.$, Fig. 7 a) that is lower than the relative tangential velocity $\left(w_{\theta}^{\prime}\right.$, Fig. $\left.7 \mathrm{c}\right)$. This produces an increase of the relative flow angle ( $\beta_{\text {flow }}^{\prime}$, Fig. 1) and a consequent positive incidence tendency. 


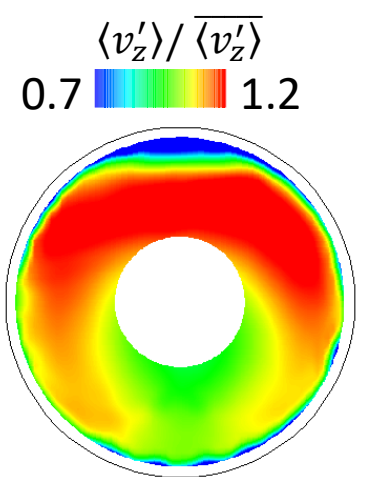

a) $\left\langle v_{\theta}^{\prime}\right\rangle / \overline{\left\langle v_{z}^{\prime}\right\rangle}$
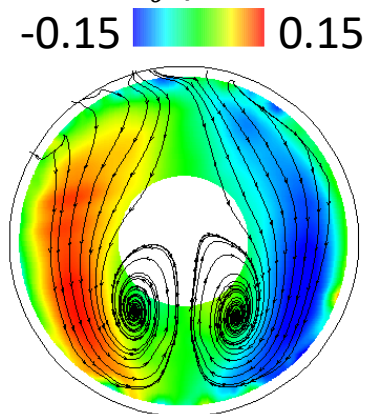

b) $\left\langle w_{\theta}^{\prime}\right\rangle \overline{\left\langle v_{z}^{\prime}\right\rangle}$
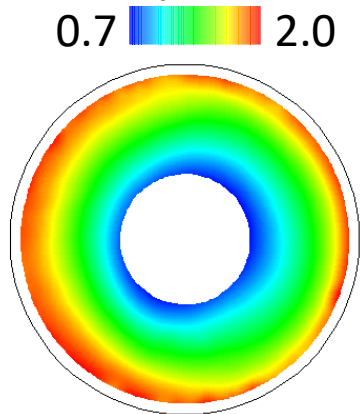

c) $\langle\iota\rangle\left(^{\circ}\right)$

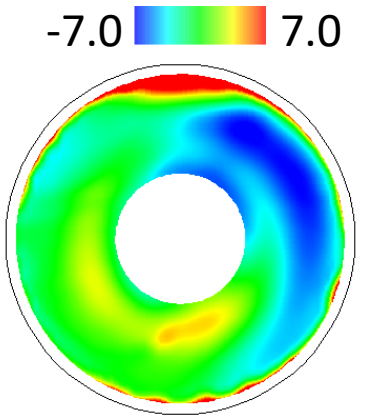

d)

Fig. 7: Time-averaged flow field with nominal inlet boundary layer $\left(\delta / D_{\text {in }}=0.04\right)$.

The distribution of the incidence velocity across the AIP highlights the possible flow compatibility issues between the curved intake and the rotor compressor. During the revolution, the rotor blades experience several changes of incidence that could reduce the compressor performances and excite the vibrational response of the rotor [28]. Recent studies showed that vortex-induced swirl events could cause a substantial reduction in the compressor total pressure ratio [29]. The areas that are subject to off-design conditions are visible in the time history of the blade incidence angle (Fig. 8). Different situations are highlighted in Fig. 8 at the locations a), b) and c). At the position a), the incidence angle is biased negative across all the blade, therefore, the blade loading is decreased in comparison to the design point. At the position $\mathrm{b}$ ), the incidence angle is close to $0^{\circ}$, so the blade loading is likely to be increased. At the position c), the incidence angle is positive near the hub while it is negative near the tip, so the blade is experiencing a nonuniform blade loading. Only 3 of the over 1200 revolutions are shown in the time history sample for 1 blade. Despite the relatively small time period, wide fluctuations by up to $\pm 24^{\circ}$ are recorded.

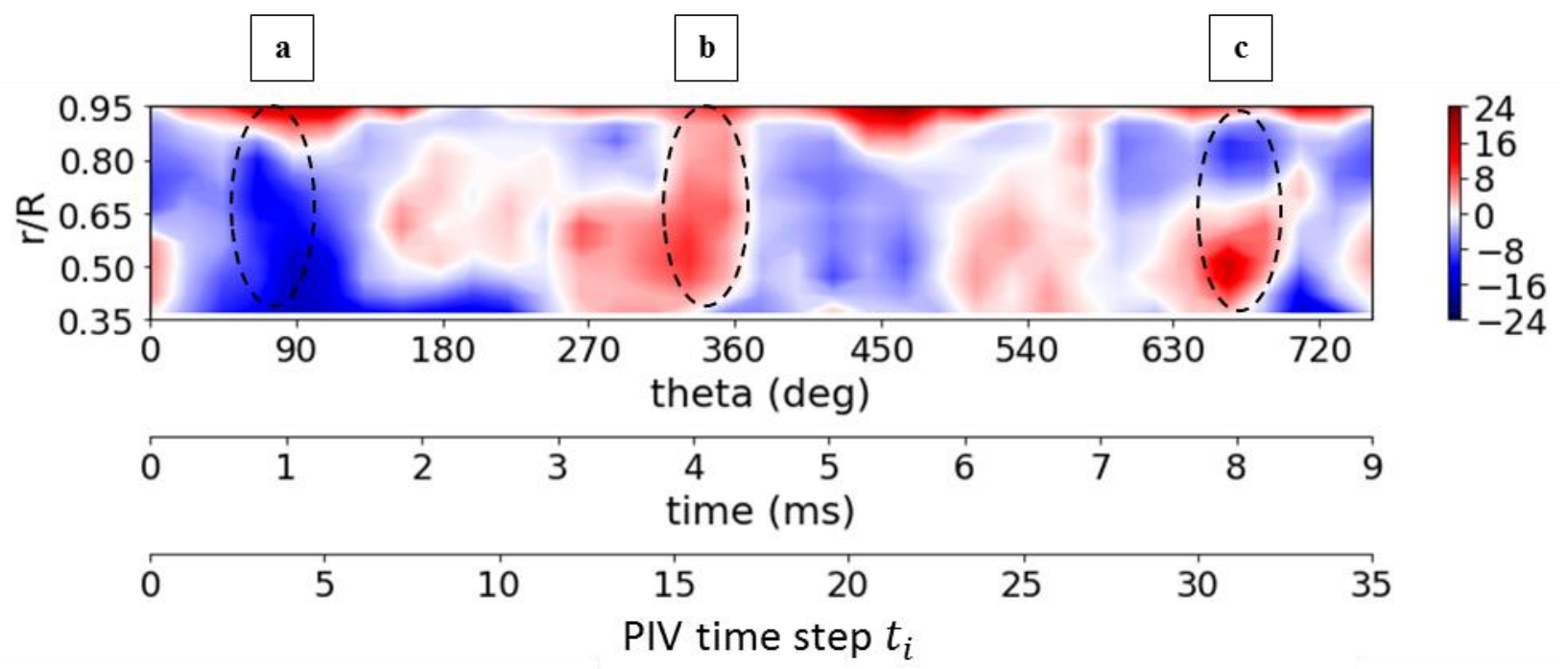

Fig. 8: Time history of a nominal R67 blade over 2 revolutions in the distorted flow field at the AIP. 


\section{B. Distortion events identification}

The tracking of the relative incidence angle has been performed for tip $(r / R=0.85)$ and hub $(r / R=0.51)$ radial positions with the time-coupling scheme explained in Fig. 3. Separate distortion events were detected with the change of sign of the relative incidence angle during the blade rotation (Fig. 4). Each event is classified with two variables: the exposure time $\left(t_{e}\right)$, which is the time the event persists on the blade during the rotation $\left(\theta_{b n}\right)$, and the magnitude, which can be either the mean or the peak value within the exposure time $\left(\langle\iota\rangle_{e}\right.$ and $\iota_{\text {peak,e }}$, Fig. 4). This identification allows to represent the data in a Cartesian grid in which the exposure time is on the horizontal axis and the mean or peak value are in the vertical axis (Fig. 9). The resolution of the exposure time is set by the rotation angle between two successive TR-PIV snapshots $\left(\Delta \theta_{b}=22.1^{\circ}\right)$. Therefore, this sets the horizontal grid spacing of the exposure maps (Fig. 9). The mean and peak value of the incidence angle is interpolated in steps of $1^{\circ}$, which sets the vertical grid spacing of the maps. Thus, the distortion events that are identified in the TR-PIV dataset populate the grid depending on the magnitude and the exposure sector. In the exposure maps, the probability of the events is computed by enumerating all the events characterized by the same magnitude and exposure sector. The value is then normalized by the total number of distortion events that are shown in the map. The wide range of probabilities is covered with a logarithmic probability color scale. The boundary between event detection-no detection in the exposure-magnitude plane is delimitated with the dashed line (Fig. 9). The total number of distortion events that are detected over 1200 rotor revolutions, considering the rotor clocking construct (Fig. 9), is 1.3 million for the tip position $(r / R=0.85)$ and 0.9 million for the hub position $(\mathrm{r} / \mathrm{R}=0.51)$ approximately.
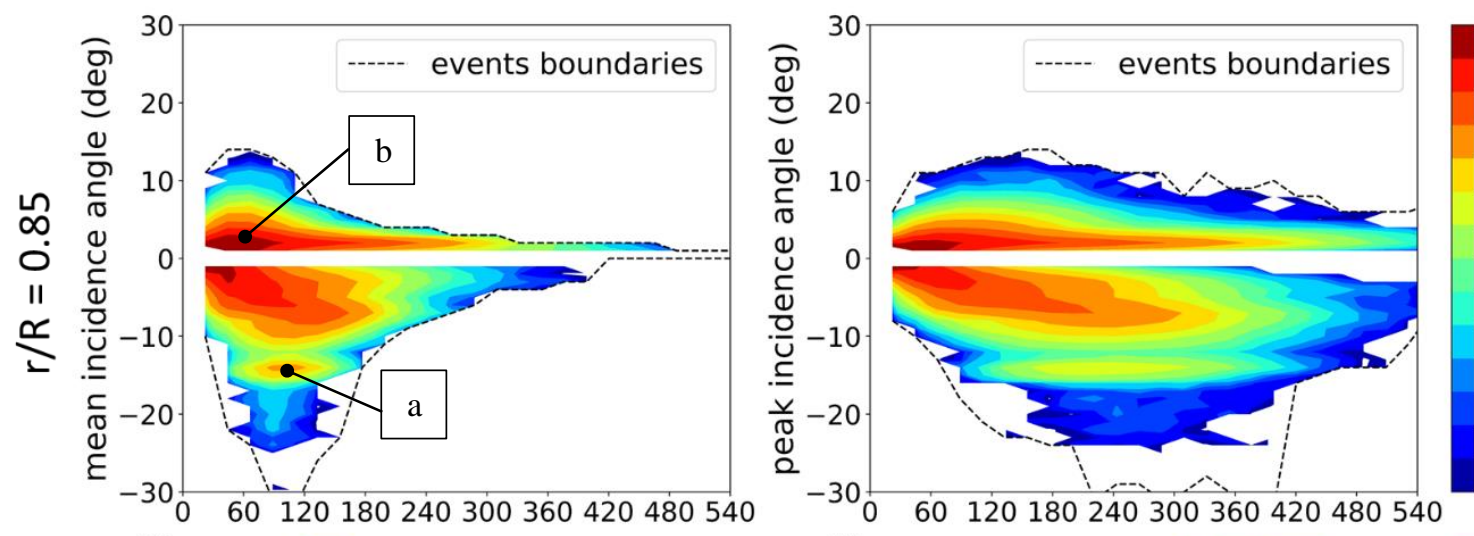

$5 e-02$

$2 \mathrm{e}-02$

$1 \mathrm{e}-02$

$5 \mathrm{e}-03$

$2 e-03 \pm$

$1 \mathrm{e}-03 \overline{\mathrm{0}}$

$5 \mathrm{e}-04$ 웅

2e-04은

$1 \mathrm{e}-04$ 은

5 e-05 $\stackrel{2}{\stackrel{1}{c}}$

$2 \mathrm{e}-05 \stackrel{0}{>}$

$1 \mathrm{e}-05 \approx$

$5 e-06$

$2 \mathrm{e}-06$

$1 \mathrm{e}-06$
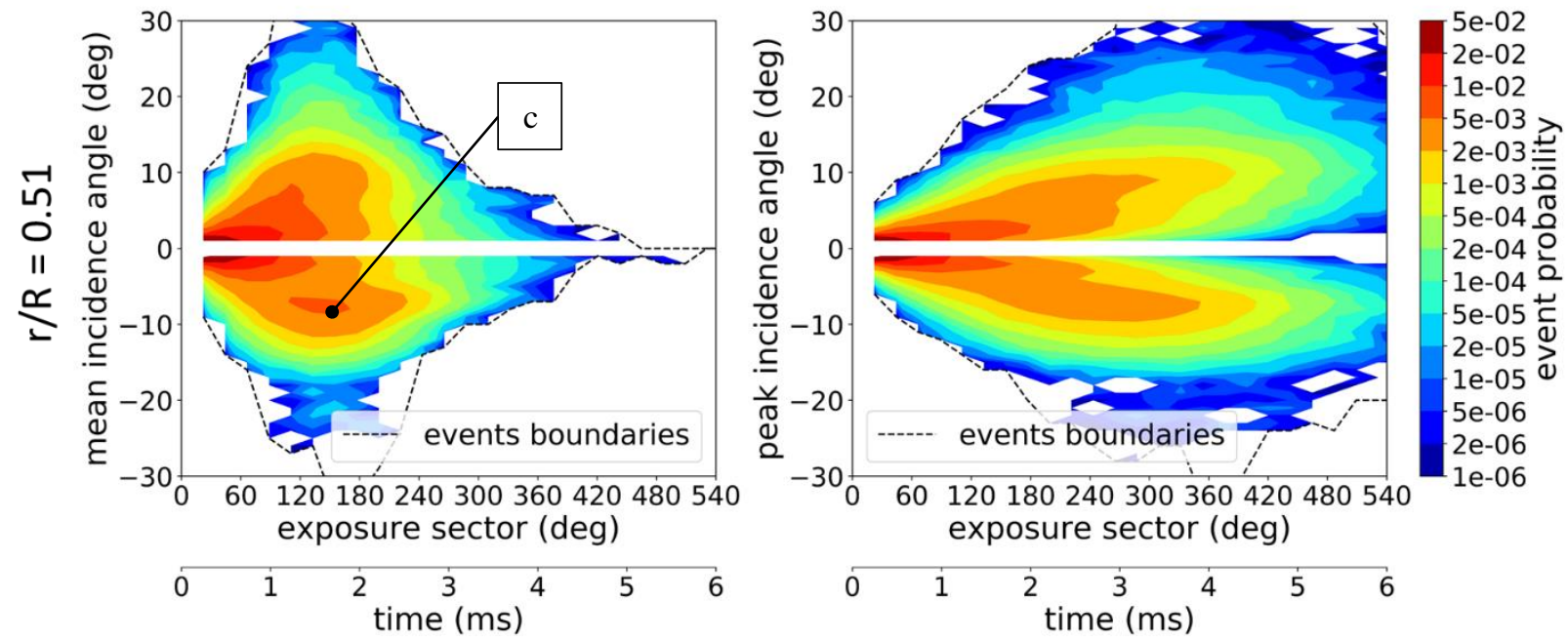

Fig. 9: Probability maps for distortion events with nominal inlet boundary layer $\left(\delta / D_{\text {in }}=0.04\right)$ for hub $(r / R=$ $0.51)$ and tip $(r / R=0.85)$ positions. 
In Fig. 9, for a position close to the tip $(\mathrm{r} / \mathrm{R}=0.85)$, the value of the mean relative incidence angle perturbations is between $-30^{\circ}$ and $+15^{\circ}$. The bias towards a negative value can be explained with the time-averaged distribution of the incidence angle (Fig. 10), which features a well-defined negative angle zone in the right hand side of the measuring plane. In particular, at the position a), the events are characterized with a mean incidence of $-13^{\circ}$ and exposure of about $120^{\circ}$ and they may be related to the rotation of the blade in the negative loading sector shown in the timeaveraged relative incidence (Fig. 10). The events in a) (Fig. 9) is characterized by a probability of $0.5 \%$ of the total distortion events of the TR-PIV dataset at $r / R=0.85$. Moreover, it is characterized by an important deviation from the nominal incidence on the rotor blades. Therefore, it could cause a notable reduction of the compressor performances and trigger instabilities in the form of flow separations on the blades. On the other hand, the high probability events with positive incidence at b) (Fig. 9) can relate to the flow separation caused by the secondary bend of the S-duct intake. This is visible in the top section boundary in out-of-plane velocity component (Fig. 7a) and it is reflected in the time-averaged incidence angle distribution (Fig. 10). The peak event probability at the same radial position $(\mathrm{r} / \mathrm{R}=$ 0.85 - Fig. 9) shows a range of peak events between $+14^{\circ}$ and $-34^{\circ}$.

At the hub ( $r / R=0.51$, Fig. 9), there is more balance between the probability of positive and negative incidence angle of the events. This is visible both in the mean and the peak incidence probability map (Fig. 9). However, traces of highly probable negative incidence events are still visible at location c). These feature an exposure sector of $120^{\circ}$ to $180^{\circ}$ and a mean incidence of $-9^{\circ}$. Therefore, it is theorized that these events could happen simultaneously all over the inner and outer radial span of the blade and they could cause a synchronous disturbance to the compressor rotor. Overall, the most frequent events are characterized by incidence angles of $\pm 1^{\circ}$ to $\pm 5^{\circ}$ and exposure between $0^{\circ}$ and $90^{\circ}$.

Generally, the exposure maps show that the most probable events are characterized by a relatively modest relative incidence angle. However, of particular interest for the engine stability assessment are the peak events, which could trigger the spike-type stall inception. Recent studies highlight the trend between the variation of the relative incidence and the associated variation in the compressor pressure ratio [29]. For example, positive incidence events are likely to change the operating point of the compressor towards a higher pressure ratio and consequently to reduce the surge margin. Although some of the peak events are characterized by a relatively small exposure sector, some of the blades were exposed to high peak incidence events along exposure sectors of more than $360^{\circ}$. This events could be related to the unsteady switching mode observed by Gil-Prieto et al. [17], which is characterized by an oscillation between positive and negative bulk swirl events.

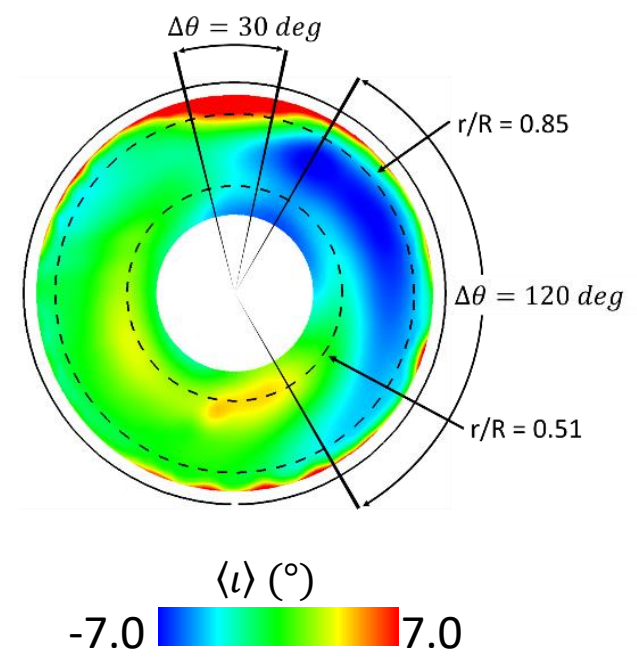

Fig. 10: Time-averaged incidence angle on R67. 


\section{Effect of inlet boundary layer thickness on distortion events}

A gauze screen placed at section 3 (Fig. 1) was used to increase the inlet boundary layer from nominal conditions $\left(\delta / D_{\text {in }}=0.04\right)$ to Profile $A\left(\delta / D_{\text {in }}=0.332\right)$. The flow asymmetry caused by the increased boundary layer thickness does not affect the general flow topology of the out-of-plane velocity and the tangential velocity (Fig. 11a-b). However, the thicker boundary layer produces an early separation in the S-duct which produces a growth of the contra-rotating vortices at the AIP (Fig. 11b). The mass flow non-uniformity favors the downward pitching flow of the S-duct which strengthens the secondary flows (Fig. 11b) and accentuates the momentum non-uniformity at the AIP (Fig. 11a). The tangential component of the relative velocity remains broadly unaltered (Fig. 11c), since it is mainly influenced by the rotational speed of the rotor. With the inlet Profile A $\left(\delta / \mathrm{D}_{\text {in }}=0.332\right)$, the time-averaged relative incidence angle (Fig. 11d) shows more pronouncedly the areas of positive and negative incidence of the baseline case (Fig. 10). The peak time-averaged value increases from the range $\left[-6^{\circ},+4^{\circ}\right]$ to $\left[-9^{\circ},+7^{\circ}\right]$.

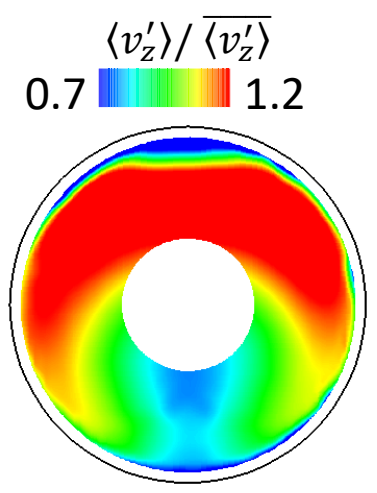

a)

$$
\left\langle v_{\theta}^{\prime}\right\rangle / \overline{\left\langle v_{z}^{\prime}\right\rangle}
$$
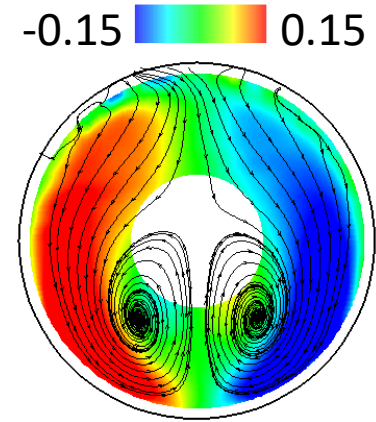

b)

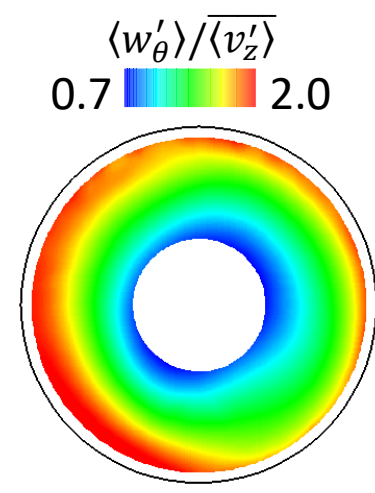

c) $\langle\iota\rangle\left({ }^{\circ}\right)$

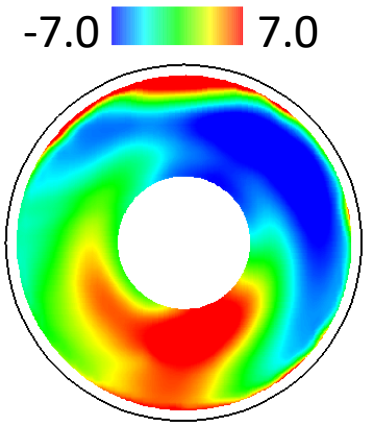

d)

Fig. 11: Time-averaged flow field with inlet Profile $A\left(\delta / D_{\text {in }}=0.332\right)$.

In general, the exposition of the S-duct to a thicker inlet boundary layer (Profile $A, \delta / D_{\text {in }}=0.332$ ) increased the probability of distortion events that are characterized by longer exposure sector (Fig. 12). This is noticeable by comparing the magnitude and exposure sector of high probability events with the baseline inlet boundary layer (Fig. 9). For example, $2 \%$ of the total detected events at $\mathrm{r} / \mathrm{R}=0.85$ have an exposure sector within $0^{\circ}$ to $180^{\circ}$ (Fig. 12), while events with the same probability and same $r / R=0.85$ have an exposure sector between $0^{\circ}$ and $120^{\circ}$ for the baseline inlet condition (Fig. 9).

Relative to the nominal inlet boundary layer, the thicker boundary layer (Profile $A, \delta / \mathrm{D}_{\text {in }}=0.332$ ) has a relatively minor effect on the extreme mean values of the events (Fig. 12), which range between $-32^{\circ}$ and $+14^{\circ}$ at tip $(\mathrm{r} / \mathrm{R}=$ $0.85)$ and between $-35^{\circ}$ and $+33^{\circ}$ at the hub $(r / R=0.51)$. These are broadly unaffected if compared to the incidence values for the same radial positions with the baseline inlet condition $\left(\delta / \mathrm{D}_{\text {in }}=0.04\right.$, Fig. 9$)$. However, there is a notable change in the events boundaries for relatively long exposure sectors. At the hub $(\mathrm{r} / \mathrm{R}=0.51$, Fig. 12), the range of the mean value of events with $360^{\circ}$ exposure sectors increases from $\left[5^{\circ},-8^{\circ}\right]$ to $\left[12^{\circ},-10^{\circ}\right]$ relative to the baseline inlet boundary layer $\left(\delta / \mathrm{D}_{\text {in }}=0.04\right.$, Fig. 9$)$.

The thickness of the boundary layer influenced the probability of peak distortion events which are characterized by a relatively high exposure sector (i.e. bulk swirl events) and positive incidence. For example, at the tip $(\mathrm{r} / \mathrm{R}=0.85$, Fig. 12) the probability of events with $+10^{\circ}$ peak incidence doubled from $1 / 1 \times 10^{6}$ to $1 / 5 \times 10^{5}$ relative to the baseline case $\left(\delta / D_{\text {in }}=0.04\right.$, Fig. 9$)$. The same effect is noticeable for the hub position $(r / R=0.51$, Fig. 12$)$, where the probability of events with $+10^{\circ}$ peak incidence and $360^{\circ}$ exposure sector increased from 1/1,000 to 1/200 relative to the baseline case $\left(\delta / D_{\text {in }}=0.04\right.$, Fig. 9$)$.

The increase of the inlet boundary layer thickness produced also specific high-probability events which are highlighted at positions a) and b) (Fig. 12). The negative incidence events at a) feature a probability up to $1 \%$ and they are contained within an exposure sector of $120^{\circ}$ to $210^{\circ}$, which is a wider range compared to the nominal inlet case (Fig. 9, position a). The magnitude of these events varies between $-12^{\circ}$ and $-13^{\circ}$, which is broadly unaltered if compared to the nominal inlet case. A symmetric location on the map (Fig. 12, position b) highlights also highly probable events with a positive incidence angle. These events have probability up to $1 \%$, exposure sector between $150^{\circ}$ to $180^{\circ}$ and mean incidence values contained within $+8^{\circ}$ to $+10^{\circ}$. 

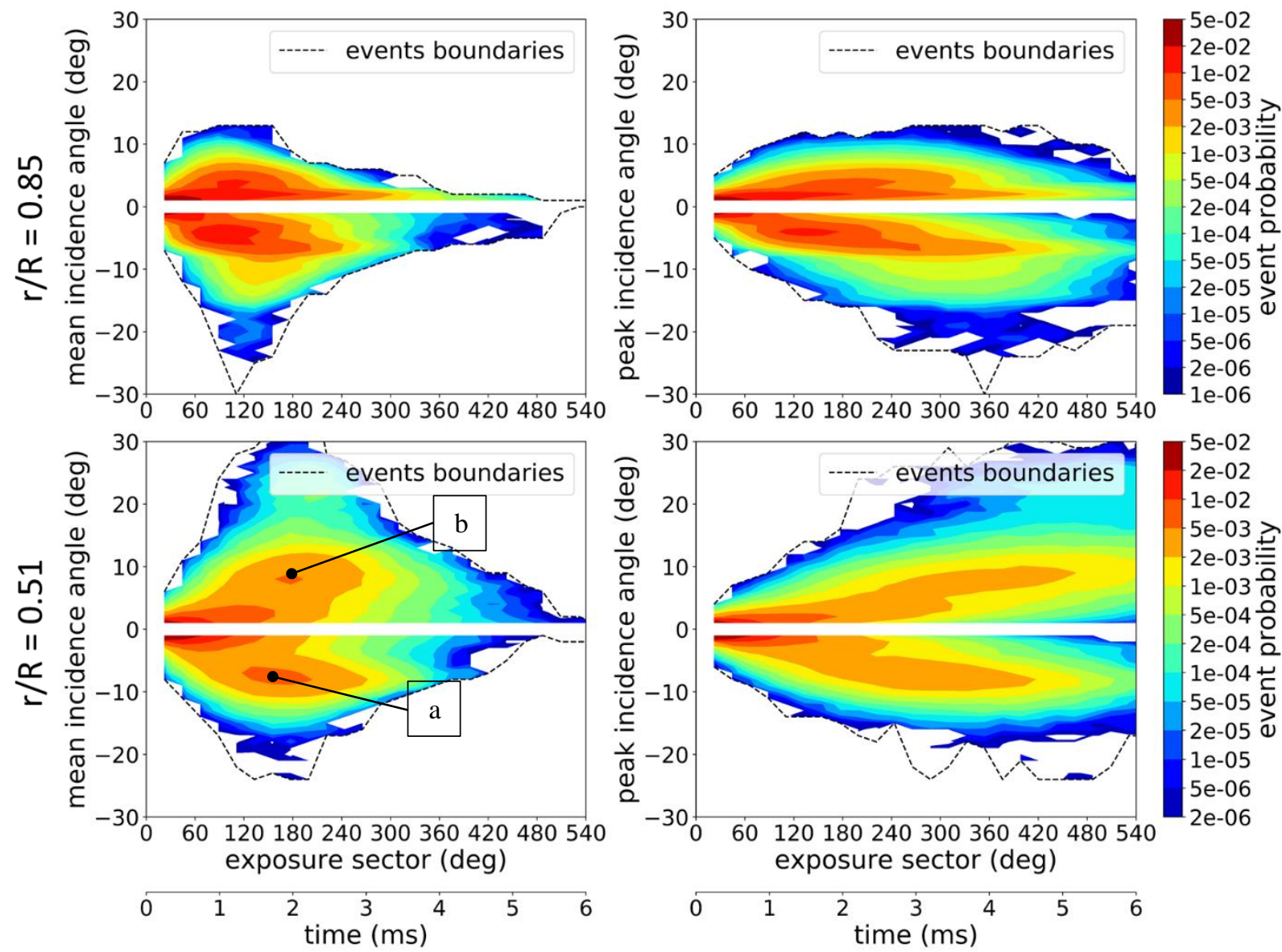

Fig. 12: Probability maps for distortion events with inlet Profile $A\left(\delta / D_{\text {in }}=0.332\right)$ for hub $(r / R=0.51)$ and tip $(\mathbf{r} / \mathbf{R}=\mathbf{0 . 8 5})$ positions.

\section{Effect of inlet boundary layer orientation on distortion events}

To represent inlet conditions of an intake under angles of pitch and yaw [30], the azimuthal orientation of the inlet flow Profile A $(\delta /$ Din $=0.332)$ was varied starting from the high pressure loss region at bottom dead center $\left(\psi=0^{\circ}\right.$ ) to angles of $\psi=45^{\circ}, 90^{\circ}$ (Fig. 13). The rotation of the screen by $\psi=45^{\circ}$ produced an increase of the number of positive incidence angle events in comparison with the baseline case $\left(\psi=0^{\circ}\right.$, Fig. 14). The maximum mean relative incidence angle increased from $+13^{\circ}$ up to $+20^{\circ}$, while the minimum mean incidence remained constant at about $-30^{\circ}$ in comparison with the baseline case $\left(\psi=0^{\circ}\right)$. The increase of positive incidence events is also noticeable in the peak incidence map for $\psi=45^{\circ}$, where positive boundary increased from $+14^{\circ}$ to $+20^{\circ}$ relative to the $\psi=0^{\circ}$ orientation. While the maximum magnitude of the events increases, on the other hand, the exposure sector associated with these events decreases. For $\psi=45^{\circ}$, the maximum mean incidence event has an associated exposure sector of $60^{\circ}$, which is approximately half of the exposure time for the maximum mean event at $\psi=0^{\circ}$ (Fig. 14).

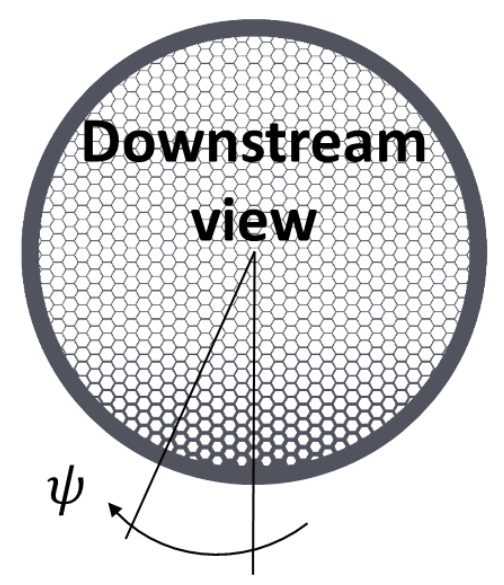

Fig. 13: Rotation of the screen to shift the high pressure loss region from bottom dead center to $\psi=45^{\circ}$ and $90^{\circ}$. 
When the screen is rotated by $\psi=90^{\circ}$, there is a modest reduction of the maximum mean and maximum peak values of the events, accompanied by a noticeable reduction of the maximum exposure sector. The event with the highest mean incidence reduced from $+20^{\circ}$ to $+18^{\circ}$ if compared with the screen oriented at $\psi=45^{\circ}$. For $\psi=90^{\circ}$, less than $1 / 1 \times 10^{\wedge} 6$ events are characterized by an exposure sector wider than $360^{\circ}$.

Overall, the inlet boundary layer orientation has a weak influence on the most probable events, which are contained in a region between $\pm 5^{\circ}$ mean incidence and an exposure sector up to $180^{\circ}$. However, when the inlet boundary layer is oriented at $\psi=90^{\circ}, 5 \%$ on the total number of identified events at $\mathrm{r} / \mathrm{R}=0.85$ have a exposure sector of $120^{\circ}$ and a mean negative incidence of about $-5^{\circ}$ (position a, Fig. 14). In addition, $0.2 \%$ of the events can have a peak value of $+7^{\circ}$ over an exposure sector up to $240^{\circ}$. Although the magnitude of these event is low compared to the maximum mean and peak values of the events at the boundaries, their high probability and their significant exposure sector could severely affect the stability of the propulsion system. This flags probable compatibility issues of the coupling between the compressor and the intake for operating conditions that are typical of high yaw and high pitch angle.

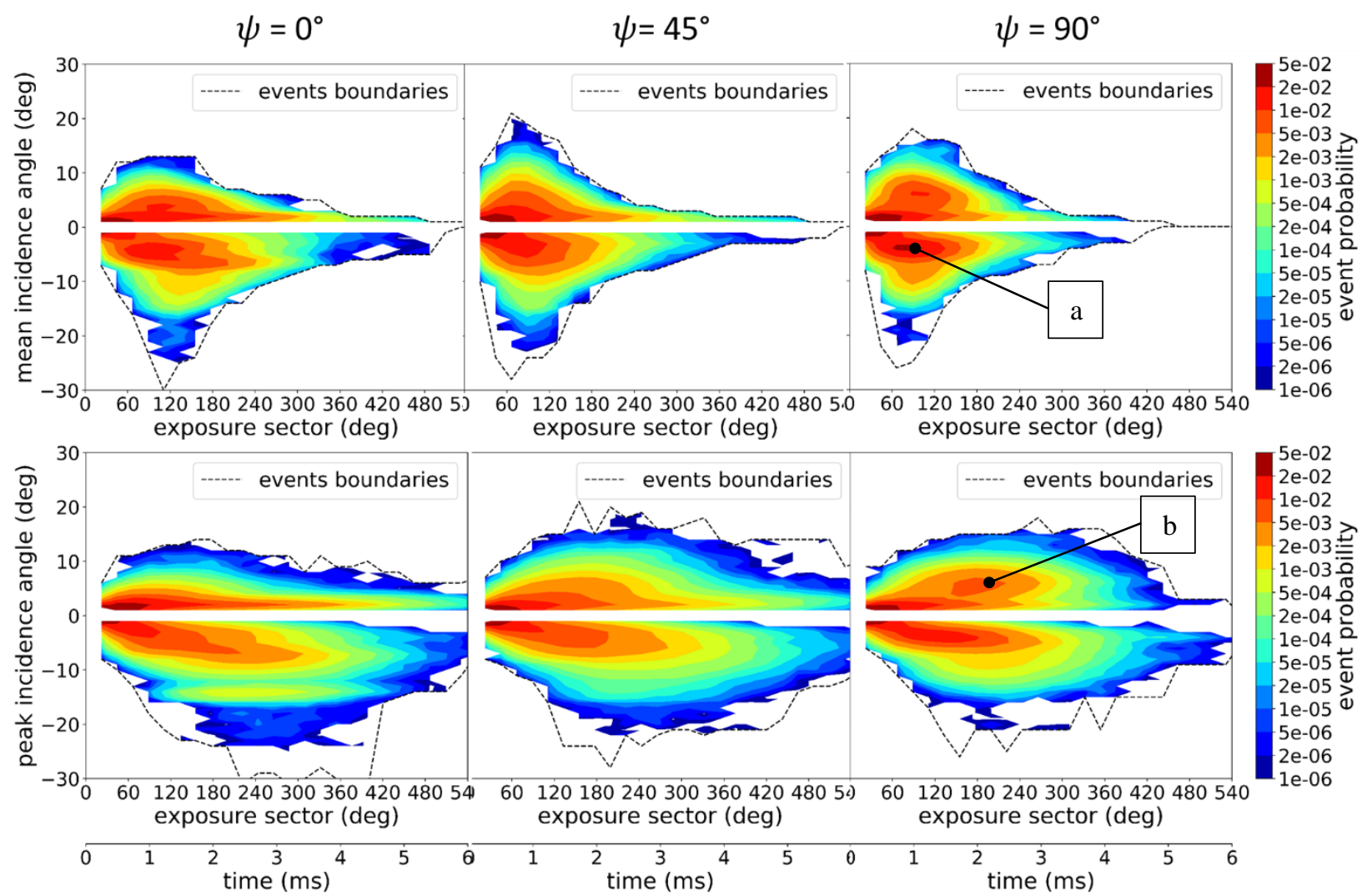

Fig. 14: Probability maps for distortion events with inlet Profile $A\left(\delta / D_{\text {in }}=0.332\right)$ with different orientations at $\mathbf{r} / \mathbf{R}=\mathbf{0 . 8 5}$. 


\section{Conclusion}

Unsteady measurements at the exit of an S-duct intake were acquire with Time-Resolved Particle Image Velocimetry, which provided non-intrusive synchronous 3-component velocity measurements. The data was analyzed from the perspective of the hypothesized relative frame of reference of a reference compressor rotor. The time coupling between the rotational frequency of the rotor and the acquisition frequency of the TR-PIV kit was used to assess the hypothetical relative incidence angle on the rotor blade. Distortion events were evaluated for the virtual rotation of the rotor blades in the unsteady flow field and they were classified by means of the time the blade was exposed to the distortion event, the relative incidence of the distortion events and their probability.

For the baseline inlet boundary layer, the analysis revealed that the probability distribution of the distortion events depends on the radial position at which the incidence is evaluated. A noticeable tendency towards negative relative incidence angle events was observed at the tip. Instead, at the hub, the events were distributed more equally between positive and negative incidence. Overall, very high peaks of relative incidence up to $+15^{\circ}$ and $-35^{\circ}$ were detected.

Thicker inlet boundary layers were found to have a first order impact on the likelihood of distortion events with long exposure sector. Both the probability and the incidence magnitude of these events increased if compared to the baseline case. Instead, thicker inlet boundary layers had only a second order impact on the peak incidence events, which maximum levels are broadly unaffected relative to the baseline inlet condition. Different operating conditions of the S-duct intake were re-created by changing the azimuthal position of the inlet boundary layer. This had a modest influence on the probability distribution of the distortion events. A slight increase in the mean incidence of the extreme events and a modest reduction of the exposure sector associated with these events was observed.

Overall, this work provides some insights on the S-duct intakes flow distortion from a non-conventional perspective. The conversion of the data in the envisaged relative frame of reference provided information on the severity of the distortion events at which the rotor blades are exposed during the rotation. The classification of the events by means of their magnitude and the exposure time quantified the probability of extreme events that could generate instability to the compressor rotor.

\section{Acknowledgments}

Mr. Migliorini is partially funded by UK Engineering and Physical Sciences Research Council. Due to commercial confidentiality agreements the supporting data is not available.

\section{References}

[1] Bowditch, D., and Coltrin, R., "A survey of inlet/engine distortion compatibility," NASA-TM-83421, 1983.

[2] Reid, C., "The Response of Axial Flow Compressors to Intake Flow Distortion," ASME 1969 Gas Turbine Conference and Products Show, 1969, doi: 10.1115/69-GT-29.

[3] SAE, “A Methodology for Assessing Inlet Swirl Distortion,” 2007.

[4] Cousins, W. T., "History, philosophy, physics, and future directions of aircraft propulsion system / inlet integration," Proceedings of the ASME Turbo Expo, Vienna, ASME, 2004, pp. 305-320.

[5] Oates, G. C., "The Aerothermodynamics of Aircraft Gas Turbine Engines," National Technical Information Service, 1978.

[6] Brimelow, B., Collins, T., and Pfefferkorn, G., "Engine testing in a dynamic environment," 10th Propulsion Conference, San Diego, AIAA, 1974.

[7] Cousins, W., "A theory for the prediction of compressor blade aerodynamic response," 34th AIAA/ASME/SAE/ASEE Joint Propulsion Conference and Exhibit, Cleveland, AIAA, 1998.

[8] Provenza, A. J., Duffy, K. P., and Bakhle, M. A., “Aeromechanical Response of a Distortion Tolerant Boundary Layer Ingesting Fan," Journal of Engineering for Gas Turbines and Power, vol. 141, 2018, doi: 10.1115/1.4040739.

[9] Tan, C. S., Day, I., Morris, S., and Wadia, A., "Spike-Type Compressor Stall Inception, Detection, and Control," Annual Review of Fluid Mechanics, vol. 42, Dec. 2009, pp. 275-300, doi: 10.1146/annurev-fluid-121108-145603.

[10] Silkowski, P. D., "Measurements of Rotor Stalling in a Matched and a Mismatched Multistage Compressor," GTL221GTL report \#221, Cambridge, 1995.

[11] Breuer, T., and Bissinger, N. C., "Basic Principles - Gas Turbine Compatibility - Gas Turbine Aspects," Encyclopedia of Aerospace Engineering, John Wiley \& Sons, 2010.

[12] Zachos, P. K., MacManus, D. G., Prieto, D. G., and Chiereghin, N., "Flow Distortion Measurements in Convoluted Aeroengine Intakes," AIAA Journal, vol. 54, 2016, pp. 2819-2832, doi: 10.2514/1.J054904.

[13] Tanguy, G., MacManus, D. G., Garnier, E., and Martin, P. G., "Characteristics of unsteady total pressure distortion for a complex aero-engine intake duct," Aerospace Science and Technology, vol. 78, 2018, pp. 297-311, doi: 
10.1016/j.ast.2018.04.031.

[14] Gil-Prieto, D., MacManus, D. G., Zachos, P. K., Tanguy, G., and Menzies, K. R., "Convoluted Intake Distortion Measurements Using Stereo Particle Image Velocimetry," AIAA Journal, vol. 55, 2017, pp. 1878-1892, doi: 10.2514/1.J055467.

[15] Holmes, P. I., Berkooz, G., Lumley, J. L. M., Lumley, J. L. M. engineer, and Lumley, J. L. I. mécanicien, “Turbulence, coherent structures, dynamical systems and symmetry," Cambridge, Cambridge University Press, 1996.

[16] Tanguy, G., MacManus, D. G., Zachos, P., Gil-Prieto, D., and Garnier, E., "Passive Flow Control Study in an S-Duct Using Stereo Particle Image Velocimetry,” AIAA Journal, vol. 55, 2017, pp. 1862-1877, doi: 10.2514/1.J055354.

[17] Gil-Prieto, D., Zachos, P. K., MacManus, D. G., and McLelland, G., "Unsteady characteristics of S-duct intake flow distortion," Aerospace Science and Technology, vol. 84, 2019, pp. 938-952, doi: https://doi.org/10.1016/j.ast.2018.10.020.

[18] Strazisar, A. J., and Powell, J. A., "Laser anemometer measurements in a transonic axial flow compressor rotor," NASA TP-2879, 1989.

[19] Giuliani, J. E., and Chen, J.-P., "Fan Response to Boundary-Layer Ingesting Inlet Distortions," AIAA Journal, vol. 54, 2016, pp. 3232-3243, doi: 10.2514/1.J054762.

[20] Delot, A.-L., Garnier, E., and Pagan, D., "Flow Control in a High-Offset Subsonic Air Intake," 47th AIAA/ASME/SAE/ASEE Joint Propulsion Conference \& Exhibit, AIAA, 2011.

[21] Gil-Prieto, D., Macmanus, D. G., Zachos, P. K., Tanguy, G., Wilson, F., and Chiereghin, N., "Dynamic Flow Distortion Investigation in an S-duct using DDES and SPIV data," 34th AIAA Applied Aerodynamics Conference, Washington DC, AIAA, 2016.

[22] Raffel, M., Willert, C. E., Wereley, S. T., Kompenhans, J., Willert, S., Wereley, S. T., and Kompenhans, J., "Particle Image Velocimetry: A Practical Guide," Berlin, 2007.

[23] Ingemar, S., "Test of an UCAV Air Inlet Duct (Eikon) at Static Conditions In FOI Suckdown Facility," Stockholm, 2005.

[24] Rademakers, R. P. M., Niehuis, R., and Stößel, M., "Steady and Unsteady Flow Phenomena in an Engine Intake Research Duct With and Without Passive Flow Control," Proceedings of GPPS Forum 18, Montreal, Global Power and Propulsion Society, 2018, p. 7.

[25] Garnier, E., "Flow Control by Pulsed Jet in a Curved S-Duct: A Spectral Analysis," AIAA Journal, vol. 53, 2015 , pp. 2813-2827, doi: 10.2514/1.J053422.

[26] Owens, L. R., Allan, B. G., and Gorton, S. A., "Boundary-Layer-Ingesting Inlet Flow Control," Journal of Aircraft, vol. 45, 2008, pp. 1431-1440, doi: 10.2514/1.36989.

[27] Dean, W. R., "Note on the motion of fluid in a curved pipe," The London, Edinburgh, and Dublin Philosophical Magazine and Journal of Science, vol. 4, 1927, pp. 208-223, doi: 10.1080/14786440708564324.

[28] Mahmoud, A. M., and Leong, M. S., "The Effect of Non-Uniform Aerodynamic Loading on the Blade Responses," ASME 2007 Power Conference, San Antonio, ASME, 2007, pp. 299-303.

[29] Medhi, A., "Effect of Swirl Distortion on Gas Turbine Operability," Ph. D. dissertation, Propulsion Engineering Centre, School of Aerospace, Transport and Manufacturing, Cranfield University, 2014.

[30] van Dam, E., "Inlet Distortion Characterization of the Boundary Layer Ingesting D8 Aircraft," Ph. D. dissertation, Faculty of Aerospace Engineering, University of Technology, NL, Delft, 2015. 


\section{Correction: [An assessment of the unsteady flow distortion generated by an S-duct intake]}

Author(s) Name: Matteo Migliorini(1); Pavlos Zachos(1); David MacManus(1)

Author(s) Affiliations: 1. Cranfield University, Bedford, United Kingdom.

Figures Correction Notice:

1. In section III.B, Figure 9 is wrong. Please refer to the corrected figure below:
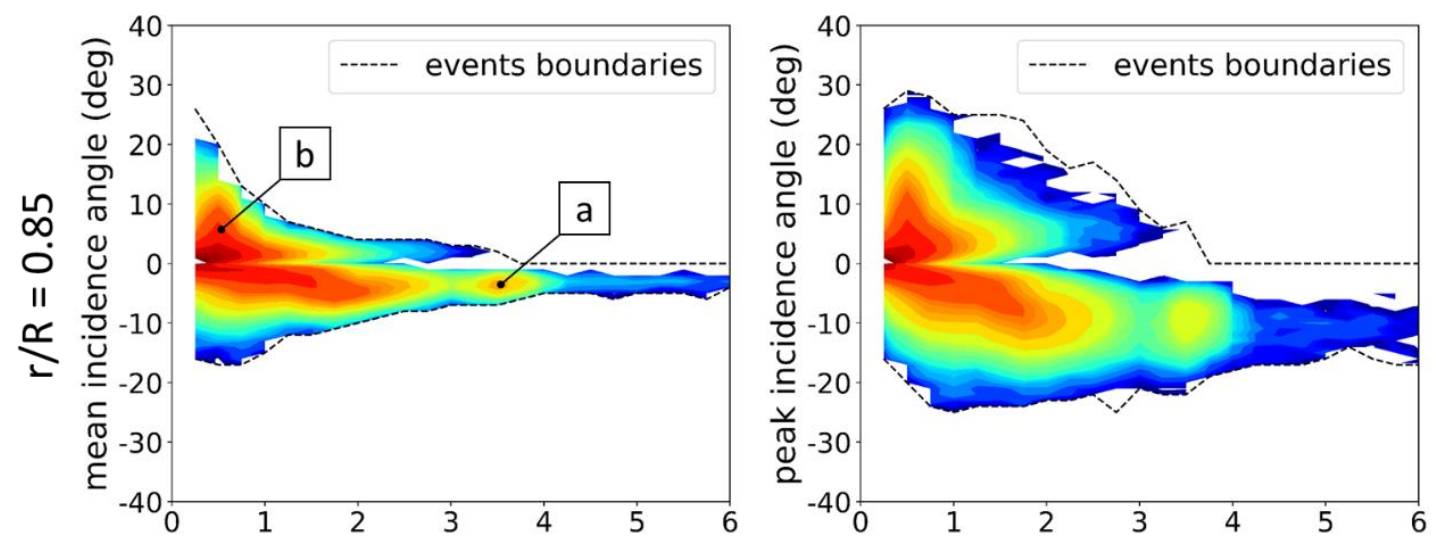

$5 e-02$

$2 \mathrm{e}-02$

$1 \mathrm{e}-02$

$5 \mathrm{e}-03$

$2 \mathrm{e}-03 \stackrel{=}{=}$

$1 e-03 \frac{0}{10}$

$5 \mathrm{e}-04$ 응

$-2 \mathrm{e}-04$ 은

$1 e-04$ 은

5e-05 든

$2 \mathrm{e}-05 \stackrel{1}{\gtrless}$

1e-05

5e-06

$2 \mathrm{e}-06$
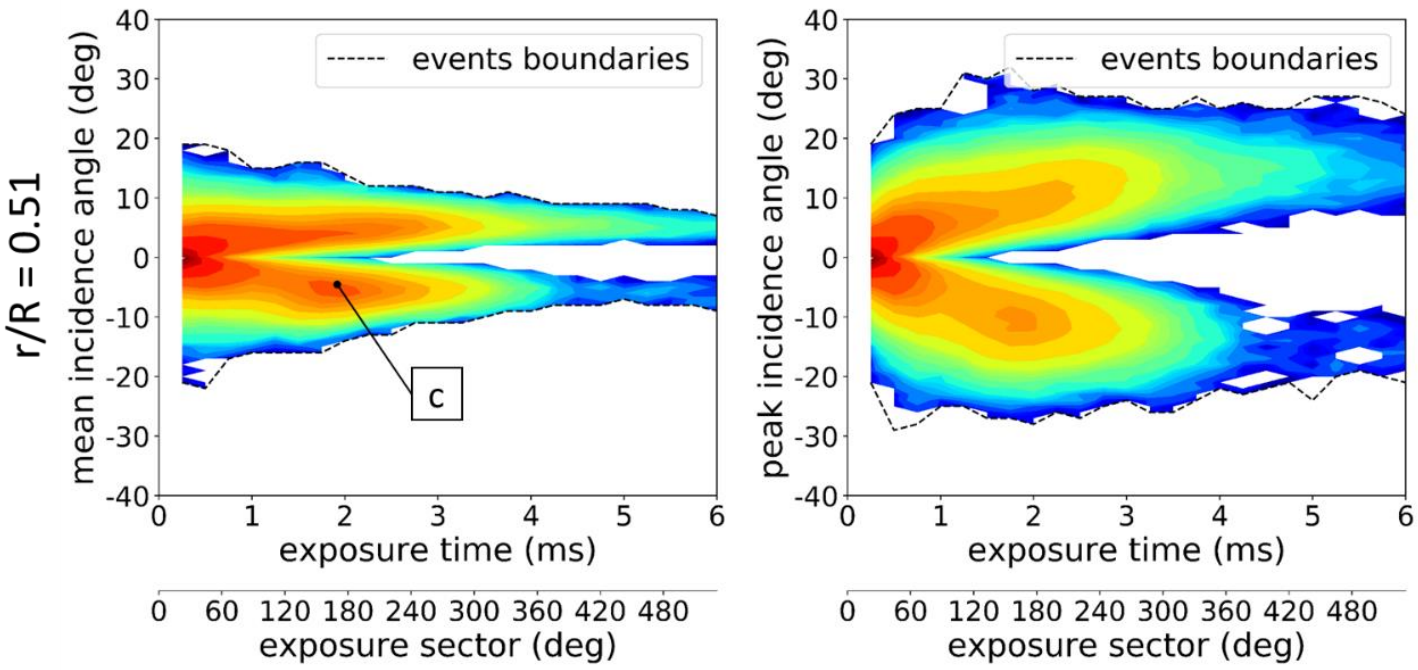

5e-02

2e-02

1e-02

-5e-03 $>$

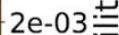

1e-03을

5e-04

-2e-04 은

1e-04 은

$5 e-05$ 든

-2e-05

le-05

5e-06

$2 \mathrm{e}-06$

$0 \quad 60120180240300360420480$ exposure sector (deg) exposure sector (deg) 
2. In section III.B, Figure 12 is wrong. Please refer to the corrected figure below:
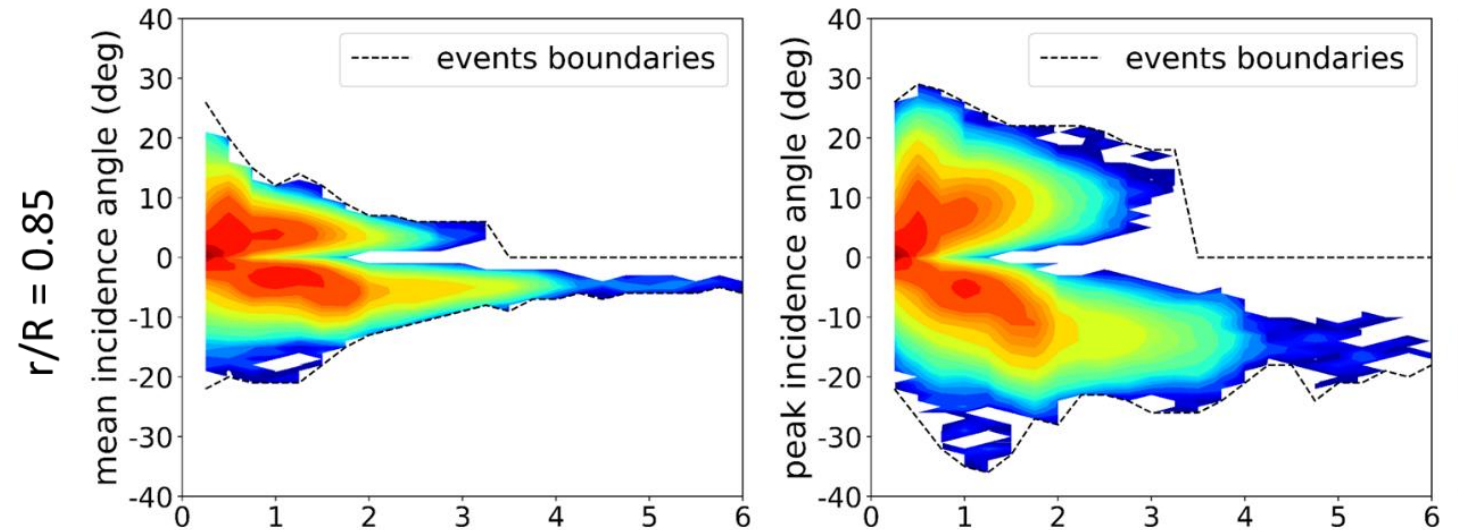

$5 e-02$

$2 \mathrm{e}-02$

$1 \mathrm{e}-02$

$5 \mathrm{e}-03>$

$2 \mathrm{e}-03 \pm$

$1 \mathrm{e}-03 \frac{0}{0}$

$5 \mathrm{e}-04 \stackrel{0}{\circ}$

$2 \mathrm{e}-04$ 은

$1 e-04$ 는

$5 \mathrm{e}-05 \stackrel{2}{\simeq}$

$2 \mathrm{e}-05 \stackrel{2}{>}$

$1 \mathrm{e}-05$

$5 e-06$

$2 \mathrm{e}-06$

$1 \mathrm{e}-06$
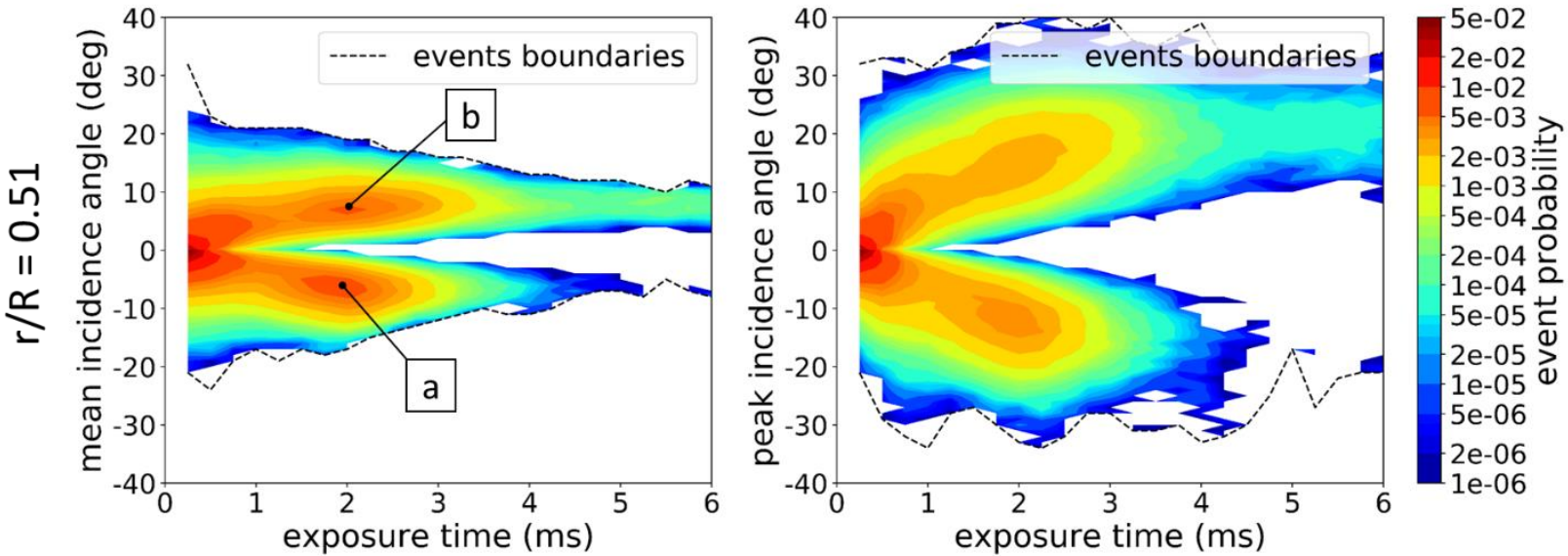

$0 \quad 60120180240300360420480$
exposure sector (deg)

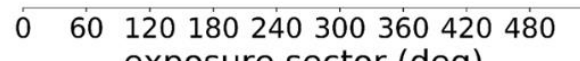
exposure sector (deg)

3. In section III.B, Figure 14 is wrong. Please refer to the corrected figure below:
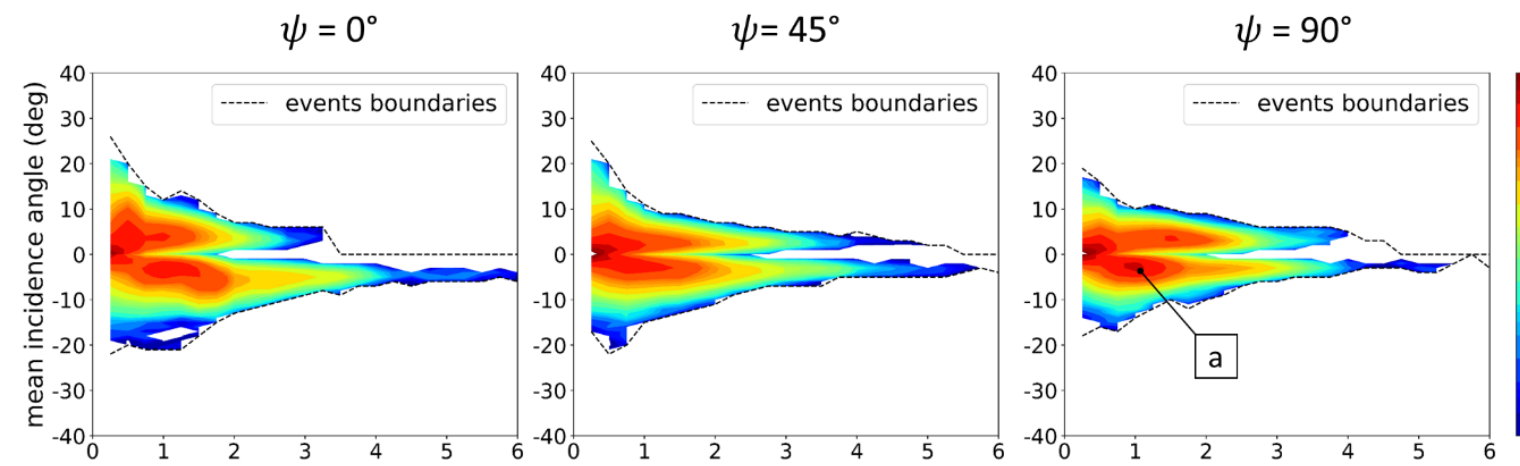

$5 e-02$

$2 \mathrm{e}-02$

$5 \mathrm{e}-03 \mathrm{e}-\mathrm{e}$

$1 \mathrm{e}-03$ -

$5 e-04 \stackrel{0}{\circ}$

$2 \mathrm{e}-04$ 은

$1 \mathrm{e}-04$

$5 \mathrm{e}-05$

$2 \mathrm{e}-05 \mathrm{~d}$

$1 \mathrm{e}-05$

$5 \mathrm{e}-06$
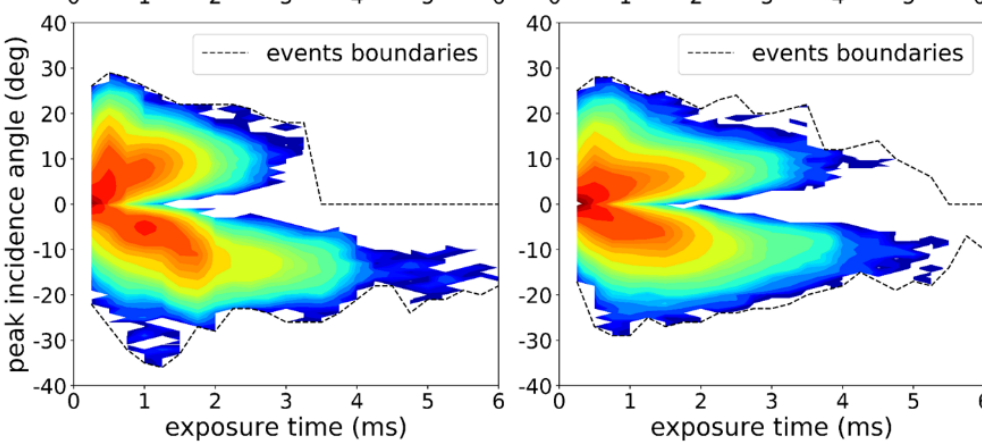$$
\begin{aligned}
& 40 \\
& 20 \\
& 10 \\
& -10 \\
& -20 \\
& -30 \\
& -40 \\
& -
\end{aligned}
$$

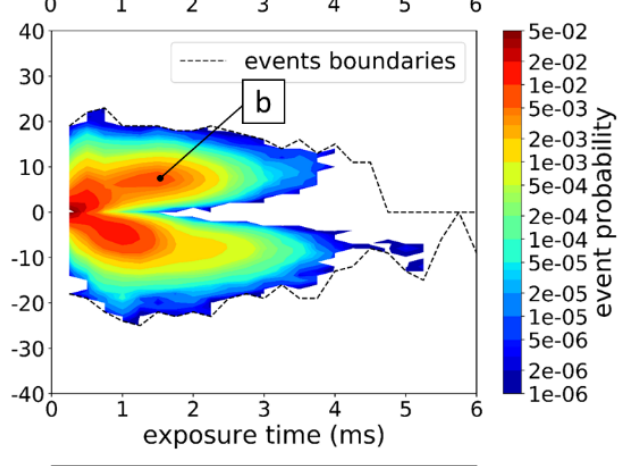

$0 \quad 60120180240300360420480$
exposure sector (deg)

$0 \quad 60120180240300360420480$
exposure sector (deg)

$0 \quad 60120180240300360420480$ exposure sector (deg) 


\section{Text Correction Notice:}

1. In section III.B, second paragraph, the sentence:

"In Fig. 9, for a position close to the tip $(\mathrm{r} / \mathrm{R}=0.85)$, the value of the mean relative incidence angle perturbations is between $-30^{\circ}$ and $+15^{\circ}$."

Should read as:

"In Fig. 9, for a position close to the tip $(\mathrm{r} / \mathrm{R}=0.85)$, the value of the mean relative incidence angle perturbations is between $-18^{\circ}$ and $+26^{\circ}$."

2. In section III.B, second paragraph, the sentence:

"In particular, at the position a), the events are characterized with a mean incidence of $-13^{\circ}$ and exposure of about $120^{\circ}$ and they may be related to the rotation of the blade in the negative loading sector shown in the time-averaged relative incidence (Fig. 10)."

Should read as:

"In particular, at the position a), the events are characterized with a mean incidence of $-5^{\circ}$ and exposure of about $360^{\circ}$ and they may be related to the rotation of the blade in the negative loading sector shown in the time-averaged relative incidence (Fig. 10)."

3. In section III.B, second paragraph, the sentence:

"The peak event probability at the same radial position $(\mathrm{r} / \mathrm{R}=0.85$ - Fig. 9) shows a range of peak events between $+14^{\circ}$ and $-34^{\circ}$."

Should read as:

"The peak event probability at the same radial position ( $r / R=0.85$ - Fig. 9) shows a range of peak events between $+29^{\circ}$ and $-36^{\circ}$."

4. In section III.B, third paragraph, the sentence:

"These feature an exposure sector of $120^{\circ}$ to $180^{\circ}$ and a mean incidence of $-9^{\circ}$."

Should read as:

"These feature an exposure sector of $150^{\circ}$ to $210^{\circ}$ and a mean incidence of $-7^{\circ}$. ."

5. In section III.B, third paragraph, the sentence:

"Overall, the most frequent events are characterized by incidence angles of $\pm 1^{\circ}$ to $\pm 5^{\circ}$ and exposure between $0^{\circ}$ and $90^{\circ}$."

Should read as:

"Overall, the most frequent events are characterized by incidence angles of $\pm 1^{\circ}$ to $\pm 3^{\circ}$ and exposure between $0^{\circ}$ and $60^{\circ}$."

6. In section III.C, second paragraph, the sentence:

"In general, the exposition of the S-duct to a thicker inlet boundary layer (Profile $A, \delta / \mathrm{D}_{\text {in }}=0.332$ ) increased the probability of distortion events that are characterized by longer exposure sector (Fig. 12)."

Should read as:

"In general, the exposition of the S-duct to a thicker inlet boundary layer (Profile $A, \delta / \mathrm{D}_{\text {in }}=0.332$ ) increased the magnitude of distortion events that are characterized by longer exposure sector (Fig. 12)."

7. In section III.C, second paragraph, the sentence:

"For example, $2 \%$ of the total detected events at $\mathrm{r} / \mathrm{R}=0.85$ have an exposure sector within $0^{\circ}$ to $180^{\circ}$

(Fig. 12Error! Reference source not found.), while events with the same probability and same $r / R=$ 0.85 have an exposure sector between $0^{\circ}$ and $120^{\circ}$ for the baseline inlet condition (Fig. 9Error!

Reference source not found.)."

Should read as: 
"For example, $2 \%$ of the total detected events at $\mathrm{r} / \mathrm{R}=0.85$ have a mean relative incidence between $-8^{\circ}$ and $+10^{\circ}$ (Fig. 12), while events with the same probability and same $r / R=0.85$ have a mean incidence between $-5^{\circ}$ and $+5^{\circ}$ for the baseline inlet condition (Fig. 9)."

8. In section III.C, third paragraph, the sentence:

"Relative to the nominal inlet boundary layer, the thicker boundary layer (Profile $A, \delta / \mathrm{D}_{\text {in }}=0.332$ ) has a relatively minor effect on the extreme mean values of the events (Fig. 12), which range between $-32^{\circ}$ and $+14^{\circ}$ at tip $(\mathrm{r} / \mathrm{R}=0.85)$ and between $-35^{\circ}$ and $+33^{\circ}$ at the hub $(\mathrm{r} / \mathrm{R}=0.51)$."

Should read as:

"Relative to the nominal inlet boundary layer, the thicker boundary layer (Profile $A, \delta / \mathrm{D}_{\text {in }}=0.332$ ) has a relatively minor effect on the extreme mean values of the events (Fig. 12), which range between $-22^{\circ}$ and $+26^{\circ}$ at tip $(\mathrm{r} / \mathrm{R}=0.85)$ and between $-24^{\circ}$ and $+33^{\circ}$ at the hub $(\mathrm{r} / \mathrm{R}=0.51)$."

9. In section III.C, third paragraph, the sentence:

"At the hub ( $\mathrm{r} / \mathrm{R}=0.51$, Fig. 12), the range of the mean value of events with $360^{\circ}$ exposure sectors increases from $\left[5^{\circ},-8^{\circ}\right]$ to $\left[12^{\circ},-10^{\circ}\right]$ relative to the baseline inlet boundary layer $\left(\delta / D_{\text {in }}=0.04\right.$, Fig. 9)."

Should read as:

"At the hub ( $\mathrm{r} / \mathrm{R}=0.51$, Fig. 12), the range of the mean value of events with $180^{\circ}$ exposure sectors increases from $\left[15^{\circ},-17^{\circ}\right]$ to $\left[20^{\circ},-19^{\circ}\right]$ relative to the baseline inlet boundary layer $\left(\delta / \mathrm{D}_{\text {in }}=0.04\right.$, Fig. 9)."

10. In section III.C, fourth paragraph, the sentence:

"For example, at the tip $\left(\mathrm{r} / \mathrm{R}=0.85\right.$, Fig. 12) the probability of events with $+10^{\circ}$ peak incidence doubled from $1 / 1 \times 10^{6}$ to $1 / 5 \times 10^{5}$ relative to the baseline case $\left(\delta / D_{\text {in }}=0.04\right.$, Fig. 9$)$."

Should read as:

"For example, at the tip $(\mathrm{r} / \mathrm{R}=0.85$, Fig. 12$)$ the probability of events with $+10^{\circ}$ peak incidence and $180^{\circ}$ exposure sector increased from $1 / 1 \times 10^{6}$ to $1 / 2 \times 10^{3}$ relative to the baseline case $\left(\delta / \mathrm{D}_{\text {in }}=0.04\right.$, Fig. 9)."

11. In section III.C, fourth paragraph, the sentence:

"The same effect is noticeable for the hub position ( $\mathrm{r} / \mathrm{R}=0.51$, Fig. 12), where the probability of events with $+10^{\circ}$ peak incidence and $360^{\circ}$ exposure sector increased from $1 / 1,000$ to $1 / 200$ relative to the baseline case $\left(\delta / \mathrm{D}_{\text {in }}=0.04\right.$, Fig. 9$)$."

Should read as:

"The same effect is noticeable for the hub position ( $\mathrm{r} / \mathrm{R}=0.51$, Fig. 12), where the probability of events with $+10^{\circ}$ peak incidence and $360^{\circ}$ exposure sector increased from 0 to $1 / 1000$ relative to the baseline case $\left(\delta / D_{\text {in }}=0.04\right.$, Fig. 9$)$."

12. In section III.C, fifth paragraph, the sentence:

"The negative incidence events at a) feature a probability up to $1 \%$ and they are contained within an exposure sector of $120^{\circ}$ to $210^{\circ}$, which is a wider range compared to the nominal inlet case (Fig. 9, position a)."

Should read as:

"The negative incidence events at a) feature a probability up to $1 \%$ and they are contained within an exposure sector of $120^{\circ}$ to $210^{\circ}$, which is a reduced exposure sector compared to the nominal inlet case (Fig. 9, position a)."

13. In section III.B, third paragraph, the sentence:

"The magnitude of these events varies between $-12^{\circ}$ and $-13^{\circ}$, which is broadly unaltered if compared to the nominal inlet case."

Should read as:

"The magnitude of these events varies between $-6^{\circ}$ and $-9^{\circ}$, which is increased if compared to the 
nominal inlet case."

\section{In section III.D, first paragraph:}

"The rotation of the screen by $\psi=45^{\circ}$ produced an increase of the number of positive incidence angle events in comparison with the baseline case $\left(\psi=0^{\circ}\right.$, Error! Reference source not found.). The maximum mean relative incidence angle increased from $+13^{\circ}$ up to $+20^{\circ}$, while the minimum mean incidence remained constant at about $-30^{\circ}$ in comparison with the baseline case $\left(\psi=0^{\circ}\right)$. The increase of positive incidence events is also noticeable in the peak incidence map for $\psi=45^{\circ}$, where positive boundary increased from $+14^{\circ}$ to $+20^{\circ}$ relative to the $\psi=0^{\circ}$ orientation. While the maximum magnitude of the events increases, on the other hand, the exposure sector associated with these events decreases. For $\psi=45^{\circ}$, the maximum mean incidence event has an associated exposure sector of $60^{\circ}$, which is approximately half of the exposure time for the maximum mean event at $\psi=0^{\circ}$ (Error!

Reference source not found.)."

Should read as:

"The rotation of the screen by $\psi=45^{\circ}$ produced limited effects on the mean and peak values probability distribution. The maximum values of the mean and the peak relative incidence is broadly unaffected in comparison with the $\psi=0^{\circ}$ orientation. However, there is an increased probability of positive peak events with exposure sector greater than $240^{\circ}$ (Fig. 13), where the top boundary reaches peaks of $25^{\circ}$. While the maximum magnitude of the events stays generally constant, on the other hand, the mean and peak values of high-probability negative incidence events decreases. For example, the mean value of negative incidence events with exposure time of about $150^{\circ}$ decreases from $-10^{\circ}$ to $-5^{\circ}$ in comparison to the baseline orientation $\left(\psi=0^{\circ}\right)$. Similarly, the peak values of these events decreases from $-12^{\circ}$ to $-8^{\circ}$ (Fig. 13)."

15. In section IV, second paragraph, the sentence:

"Overall, very high peaks of relative incidence up to $+15^{\circ}$ and $-35^{\circ}$ were detected."

Should read as:

"Overall, very high peaks of relative incidence up to $+29^{\circ}$ and $-36^{\circ}$ were detected." 
2019-08-16

\section{An assessment on the unsteady flow distortion generated by an S-duct intake}

Migliorini, Matteo

AIAA

Migliorini M, Zachos PK, MacManus DG. (2019) An assessment on the unsteady flow distortion generated by an S-duct intake. In: AIAA Propulsion and Energy 2019 Forum,19-22 August 2019, Indianapolis, IN, USA. AIAA 2019-4201. Including corrections.

https://doi.org/10.2514/6.2019-4201

Downloaded from Cranfield Library Services E-Repository 